\title{
Process Optimization and Modeling of Phenol Adsorption onto Sludge-Based Activated Carbon Intercalated MgAlFe Ternary Layered Double Hydroxide Composite
}

\author{
Nuhu Dalhat Mu'azu 1,*(D), Mukarram Zubair ${ }^{1}$ (D) and Ihsanullah Ihsanullah ${ }^{2}$ (D) \\ 1 Department of Environmental Engineering, College of Engineering, \\ Imam Abdulrahman Bin Faisal University, P.O. Box 1982, Dammam 34212, Saudi Arabia; \\ mzzubair@iau.edu.sa \\ 2 Center for Environment and Water, Research Institute, King Fahd University of Petroleum and Minerals, \\ Dhahran 31261, Saudi Arabia; engr.ihsan.dir@gmail.com or ihsankhan@kfupm.edu.sa \\ * Correspondence: nmdalhat@iau.edu.sa or dalhat@gmail.com; Tel.:+96-650-7532-689
}

Citation: Mu'azu, N.D.; Zubair, M.; Ihsanullah, I. Process Optimization and Modeling of Phenol Adsorption onto Sludge-Based Activated Carbon Intercalated MgAlFe Ternary Layered Double Hydroxide Composite. Molecules 2021, 26, 4266. https:// doi.org/10.3390/molecules26144266

Academic Editor: João Valente Nabais

Received: 27 May 2021

Accepted: 6 July 2021

Published: 14 July 2021

Publisher's Note: MDPI stays neutral with regard to jurisdictional claims in published maps and institutional affiliations.

Copyright: (c) 2021 by the authors. Licensee MDPI, Basel, Switzerland. This article is an open access article distributed under the terms and conditions of the Creative Commons Attribution (CC BY) license (https:// creativecommons.org/licenses/by/ $4.0 /)$.

\begin{abstract}
A sewage sludge-based activated carbon (SBAC) intercalated MgAlFe ternary layered double hydroxide (SBAC-MgAlFe-LDH) composite was synthesized via the coprecipitation method. The adsorptive performance of the composite for phenol uptake from the aqueous phase was evaluated via the response surface methodology (RSM) modeling technique. The SBAC-MgAlFe-LDH phenol uptake capacity data were well-fitted to reduced RSM cubic model $\left(R^{2}=0.995, R^{2}\right.$-adjusted $=0.993$, $\mathrm{R}^{2}$-predicted $=0.959$ and $p$-values $\left.<0.05\right)$. The optimum phenol adsorption onto the SBAC-MgAlFe$\mathrm{LDH}$ was achieved at $35{ }^{\circ} \mathrm{C}, 125 \mathrm{mg} / \mathrm{L}$ phenol, and $\mathrm{pH}$. Under the optimal phenol uptake conditions, pseudo-first-order and Avrami fractional-order models provided a better representation of the phenol uptake kinetic data, while the equilibrium data models' fitting follows the order; Liu $>$ Langmuir $>$ Redlich-Peterson $>$ Freundlich $>$ Temkin. The phenol uptake mechanism was endothermic in nature and predominantly via a physisorption process $\left(\Delta \mathrm{G}^{\circ}=-5.33\right.$ to $\left.-5.77 \mathrm{~kJ} / \mathrm{mol}\right)$ with the involvement of $\pi-\pi$ interactions between the phenol molecules and the functionalities on the SBAC-LDH surface. The maximum uptake capacity $(216.76 \mathrm{mg} / \mathrm{g})$ of SBAC-MgAlFe-LDH was much higher than many other SBAC-based adsorbents. The improved uptake capacity of SBAC-LDH was attributed to the effective synergetic influence of SBAC-MgAlFe-LDH, which yielded abundant functionalized surface groups that favored higher aqueous phase uptake of phenol molecules. This study showcases the potential of SBAC-MgAlFe-LDH as an effective adsorbent material for remediation of phenolic wastewater
\end{abstract}

Keywords: adsorption; ternary layered hydroxides; sewage-based adsorbents; response surface methodology; phenolic wastewater treatment; nanocomposites

\section{Introduction}

The rapid proliferation of petrochemical, pesticides, drugs, polymers, dyes, and many other chemical industries result in an increased discharge of phenol-containing wastewater globally [1]. Phenol is a known hazardous pollutant and a potential carcinogen with a high potential of harming human and other living creatures. This is liable to water quality deterioration while negatively impacting the ecosystem when discharged even at a lower concentration range. This called for setting regulatory discharge thresholds worldwide with the United States Environmental Protection Agency, for instance, setting $0.1 \mathrm{mg} / \mathrm{L}$ as the upper limit for phenol in industrial effluents discharges into surface waters [2]. On the other hand, the majority of municipal as well as many industrial treatments employed activated sludge process (ASP) as the primary treatment scheme, resulting in the generation of a huge amount of sludge globally [1,3]. The proper management of sludge is a serious issue that consumes a significant budget of the whole ASP [1]. Thus, a more sustainable 
strategy needs to be adopted for the management of sewage sludge, with a desirable shift from conventional incineration or landfilling, which are more prone to impact the environment negatively.

In recent years, conversion of the ASP sludge (ASPS) to activated carbon adsorbents for water pollution control has been identified as an effective approach to sustainable management of the ASPS [1,4,5]. The use of sludge-based activated carbon (SBAC) for the removal of phenols from water has received increased attention for its dual benefits of high phenol uptake with a potential of significant rendering the process [1]. Yet, activated carbon adsorption is still one of the popular and attractive alternative treatment methods associated with the removal of phenol from aqueous phases compared to other treatment methods. This owes to the abundant and diverse classes of activated carbon adsorbents, their lower cost, and process simplicity. However, the recovery hurdles for the spent activated carbon particles from the treated water and of generation of residual by-products are notable demerits of the adsorption process that have driven greater interest in finding new sustainable activated carbons for water pollution control.

Amongst the several emerging high-performance adsorbents for the effective removal of phenol from the aqueous phase, there is the class of special materials known as "layered double hydroxides (LDHs)". Recently, these materials proved to be exceptional due to their unique characteristics and outstanding performance. LDHs have emerged as effective adsorbents for the aqueous removal of different classes of inorganic and organic contaminants and exhibited higher adsorption capacities compared to many other known adsorbents [6,7]. Their versatility in compositions and higher and adsorptive characteristics in terms of ion exchange, BET surface area, and lower toxicity render them adaptable and attractive materials for potential deployment toward the more efficient removal of pollutants found in water and wastewater. As a consequence, a number of research reports showcase the inherent LDH flexibility and adaptability in decoration and coupling layers of various LDHs layers with a wide range of materials such as bentonite clay [8], polymers (chitosan, starch, etc.) [9], carbonous materials such as carbon nanotube (CNT) biochar, graphene [10], $\mathrm{TiO}_{2}$ [11], and date-palm wastes [12], amongst many others [13,14]. This LDH integration was reported to have yielded improved morphology, surface and functional groups, and adsorptive characteristics (active binding sites) of the resulting nanocomposites $[7,15,16]$. Several recent studies have demonstrated high performances of different LDHs nanocomposites for the aqueous phase uptake of phenols from water and wastewater streams $[17,18]$. This included NiAl-LDH modified sodium citrate that yielded 95\% removal and $77.7 \mathrm{mg} / \mathrm{g}$ maximum adsorption capacity for phenol and p-nitrophenol, respectively [19]. Similarly, $\mathrm{MgAl}$ was reported to have resulted in better uptake capability for p-nitrophenol (356.4 mg/g) and phenol $(82.5 \mathrm{mg} / \mathrm{g})$ [20]. Moreover, Mg-Al-LDH nanocomposites with carbon nanotubes intercalation exhibited excellent potential for the uptake of 4-chlorophenol and phenol from the aqueous phase [21].

Recently, Mu'azu et al. [1] reported the utilization of sewage-based activated carbons (SBACs) for the removal of phenolic compounds from the aqueous phase. The utilization of sewage sludge for GAC production for phenol uptake has been reported using physical activation methods that included conventional and microwave heating [22] and $\mathrm{CO}_{2}$ [23], yielding maximum adsorption capacities of $32.96-34.36 \mathrm{mg} / \mathrm{g}$ and $32.4 \mathrm{mg} / \mathrm{g}$. However, chemical agent activation of SBAC apparently provided high yields with reported capacities of $20.95-81.6 \mathrm{mg} / \mathrm{g}, 2.01 \mathrm{mmol} / \mathrm{g}, 17.82-96.15 \mathrm{mg} / \mathrm{g}$, and $26.16 \mathrm{mg} / \mathrm{g}$, respectively when $\mathrm{ZnCl}_{2}$ [24,25], citric acid- $\mathrm{ZnCl}_{2}$ mixture [26], $\mathrm{NaOH}$ [25,27], and $\mathrm{H}_{2} \mathrm{SO}_{4}$ [28] were employed. Recently, Xin et al. [29] employed polymer flocculants from which they obtained a higher phenol uptake of $132.33 \mathrm{mg} / \mathrm{g}$. To improve the capacities for the reported $\mathrm{ZnCl}_{2}$ activated SBAC, Muazu et al. [17] synthesized an SBAC binary MgFe-LDH composite from which a higher capacity of $138.69 \mathrm{mg} / \mathrm{g}$ down from the earlier report, $20.9 \mathrm{mg} / \mathrm{g}$, was recorded for the SBAC.

Despite the variety of existing adsorbents for the remediation of a wide range of phenols from the water, the quest for linking novel adsorbents with sustainability in 
environmental management and water treatment necessitate emerging new research. In this regard, no work so far has reported on the ternary LDH composite with NaOH-based SBAC. Considering that $\mathrm{NaOH}$-based SBAC yielded good comparative capacity for phenol uptake [25], intercalating $\mathrm{NaOH}$-activated SBAC within the layer of a ternary LDH has a high potential for yielding a better SBAC-based adsorbent.

Response surface methodology (RSM) modeling has become an indispensable tool in scientific evaluative research [30]. As such, it was adopted in this study for the evaluation and optimization under different experimental conditions. Its numerous benefits included the ability to develop response models correlating the operational parameters with their respective interactive, statistical analysis of variances (ANOVA) and estimating the curvature of the response surface while enabling process optimizing of the sorption process with a fewer required number of experimental data points [31-34].

Thus, this work reports, for the first time, the synthesis of a novel $\mathrm{NaOH}$-based SBAC intercalated MgAlFe ternary-LDH (SBAC-MgAlFe) via a coprecipitation process and evaluation of its adsorptive potentials for the removal of phenol from the aqueous phase. Additionally, the mechanism of phenol uptake onto the SBAC-MgAlFe was studied and elucidated via kinetics as well as equilibrium and regeneration studies.

\section{Materials and Method}

\subsection{Sludge and Chemical Reagents}

The sludge used was sourced from a tertiary wastewater treatment plant managed by the Saudi Aramco facility located in Dhahran, Saudi Arabia. The collected sample was air dried immediately in an oven for 0.5 days at a temperature of $105^{\circ} \mathrm{C}$. The cooled and dried sample was ground and sieved with a $100 \mu \mathrm{M}$ mesh size sieve prior to use in the production of the SBAC. The SBAC used in the ternary MgAlFe-LDH composite in this study was produced using $\mathrm{NaOH}$ activation from precursor sludge as reported by Musliu et al. [25]. Phenol $\left(\mathrm{C}_{6} \mathrm{H}_{6} \mathrm{O}\right)$, hydrochloric acid $(\mathrm{HCl})$, sodium hydroxide $(\mathrm{NaOH})$, aluminum hexahydrate $\left(\mathrm{Al}\left(\mathrm{NO}_{3}\right)_{3} \cdot 9 \mathrm{H}_{2} \mathrm{O}\right)$, magnesium (II) nitrate hexahydrate $\left(\mathrm{Mg}\left(\mathrm{NO}_{3}\right)_{2} \cdot 6 \mathrm{H}_{2} \mathrm{O}\right)$, Iron(III) nitrate nonahydrate $\left(\mathrm{Fe}\left(\mathrm{NO}_{3}\right)_{3} \hat{\mathrm{A}} \cdot 9 \mathrm{H}_{2} \mathrm{O}\right)$, and other chemical reagents obtained from Sigma Aldrich Co (USA) were used as purchased because they are all of high purity $(>98.7 \%)$.

\subsection{Synthesis of Ternary SBAC-MgAlFe LDH Composite}

A coprecipitation process as reported by Alagha et al. [35] was employed for the hybridization of the MgAlFe with the NaOH-SBAC to produce the SBAC-MgAlFe-LDH composite. Firstly, for each molar ratio of 0.05:0.05:0.1 of the precursor salts, which were Mg:Al:Fe salts (i.e., 1.3:1.9:4.04 g), $250 \mathrm{mg}$ of the SBAC was homogeneously dispersed in $100 \mathrm{~mL}$ of the ionized water-salts mixture via ultrasonication for half an hour. The slurry of the SBAC and the salts mixture was further mixed vigorously with a magnetic stirrer in a reaction flask at a higher temperature of $90{ }^{\circ} \mathrm{C}$ for $15 \mathrm{~min}$. Afterwards, the $\mathrm{pH}$ was raised and stabilized at $10 \pm 0.5$ by the gradual dropwise addition of $1 \mathrm{M} \mathrm{NaOH}$ prior followed by refluxing for $18 \mathrm{~h}$ while maintaining the temperature at $90{ }^{\circ} \mathrm{C}$. At the end of the reaction, the produced composite SBAC-MgAlFe was separated from the supernatant water via centrifuge and then washed with deionized water and ethanol and allowed to completely dry in an oven set at $85^{\circ} \mathrm{C}$.

\subsection{Characterization of Ternary SBAC-MgAlFe LDH Composite}

The morphology and physicochemical characteristics of the SBAC-MgAlFe were determined using a thermogravimetric analyzer instrument (TGA-50 Shimadzu, Tokyo, Japan), Brunauer Emmett Teller (BET, Micromeritics, Tristar II series, Norcross, GA, USA), X-ray diffraction (XRD, D8 advance X-ray instrument, Bruker, Billerica, MA, USA, for $2 \theta$ range $70^{\circ}$ to $10^{\circ}$ and $0.1542 \mathrm{~nm}$ wavelength), scanning electron microscopy (SEM, SM-6460LV (Jeol), Tokyo, Japan), Fourier transform infrared (FTIR, Nicolet 6700, Thermo fisher, Waltham, MA, USA, resolution $4 \mathrm{~cm}^{-1}$ ), point of zero charge using the drift method [36], and a HANA, Padova, Italy $\mathrm{pH}$ meter. 


\subsection{RSM Experiments Design Matrix and Modeling}

To evaluate the adsorptive performance of the new SBAC-MgAlFe-LDH, RSM was adopted in this study due to its numerous benefits, as mentioned earlier. Under the RSM, a $3^{3}$ faced centered central composite design (FC-CCD) was adopted for investigating the dependence of maximum adsorption capacity $\left(\mathrm{q}_{\mathrm{e}}\right)$ on temperature $\left(\mathrm{A}=25-45^{\circ} \mathrm{C}\right)$, initial phenol concentration $(\mathrm{B}=22.4 \pm 2.53$ to $125 \pm 4.52 \mathrm{mg} / \mathrm{L})$, and initial $\mathrm{pH}(\mathrm{C}=2-10)$ chosen based on previously reported work [37]. The FC-CCD design composed of factorial $\left(3^{\mathrm{k}}\right)$, axial $(2 \mathrm{k})$, and replicated central $(\mathrm{k})$ runs for the $\mathrm{k}$ number of investigated factors. The CCD "star" points outside this experimental domain and the design points at the center of the experimental domain make it possible to estimate the curvature of the response surface $[33,38]$. Moreover, the FC-CCD has advantages over other forms of the CCD, as its star points are at the center of each face of the factorial space (i.e., $\alpha= \pm 1$ ), it requires fewer levels of each factor ( 3 against 5 for other design), and also it can also be achieved by augmenting an existing factorial or resolution $\mathrm{V}$ design data with appropriate star points $[33,38]$. Table 1 provides the experimental data points required to implement the FC-CCD for the phenol uptake onto SBAC-MgAlFe-LDH, which ran in triplicate. The RSM models development using Equation (1), statistical ANOVA analysis, and optimization were undertaken using Design-Expert version 9. Equation (1):

$$
e=\beta_{0}+\sum_{i=1}^{k} \beta_{i} x_{i}+\sum_{i=1}^{k} \beta_{i} x_{i}^{2}+\sum_{i=1}^{k-1} \sum_{j=2}^{k} \beta_{i j} x_{i} x_{j}+\varepsilon
$$

where $\mathrm{q}_{\mathrm{e}}=$ developed model predicted SBAC-MgAlFe-LDH adsorption capacity for phenol uptake; $\beta_{\mathrm{i} i}, \beta_{\mathrm{ij}}, \beta_{\mathrm{i}}$, and $\beta_{0}$ are the developed $\mathrm{q}_{\mathrm{e}}$ model's coefficients; $\mathrm{x}_{\mathrm{j}}, \mathrm{x}_{\mathrm{i}}$, = operational conditions.

Table 1. FC-CCD RSM experimental design matrix and results for phenol uptake onto Na-SBAC$\mathrm{MgAlFe}-\mathrm{LDH}$.

\begin{tabular}{|c|c|c|c|c|c|}
\hline \multicolumn{2}{|c|}{ Factor } & \multicolumn{2}{|c|}{ Lower Level (-1) } & \multirow{2}{*}{$\begin{array}{c}\text { Mid-Level (0) } \\
35\end{array}$} & High-Lower (+1) \\
\hline A & Temperature $\left({ }^{\circ} \mathrm{C}\right)$ & \multicolumn{2}{|c|}{25} & & 45 \\
\hline B & $\begin{array}{l}\text { Initial phenol } \\
\text { conc. (mg/L) }\end{array}$ & \multicolumn{2}{|c|}{22.4} & 73.7 & 125 \\
\hline C & Initial pH & \multicolumn{2}{|c|}{2} & 6 & 10 \\
\hline Adsorption Test & \multicolumn{3}{|c|}{ Operating Conditions } & \multicolumn{2}{|c|}{$\begin{array}{c}\text { Responses } \\
\text { Adsorption capacity (mg/g) } \\
\text { Predicted }\end{array}$} \\
\hline 1 & 35 & 22 & 6 & & 8.65 \\
\hline 2 & 35 & 73.5 & 6 & & 56.7 \\
\hline 3 & 35 & 73.5 & 10 & & 4.35 \\
\hline 4 & 25 & 73.5 & 6 & & 5.71 \\
\hline 5 & 35 & 73.5 & 6 & & 56.7 \\
\hline 6 & 35 & 125 & 6 & & 7.61 \\
\hline 7 & 35 & 73.5 & 6 & & 56.7 \\
\hline 8 & 25 & 125 & 2 & & 4.38 \\
\hline 9 & 45 & 22 & 10 & & 1.7 \\
\hline 10 & 45 & 22 & 2 & & 7.00 \\
\hline 11 & 45 & 125 & 2 & & 9.45 \\
\hline 12 & 25 & 125 & 10 & & 7.58 \\
\hline 13 & 35 & 73.5 & 2 & & 10.4 \\
\hline 14 & 25 & 22 & 2 & & 3.85 \\
\hline 15 & 35 & 73.5 & 6 & & 56.7 \\
\hline 16 & 45 & 125 & 10 & & 9.17 \\
\hline 17 & 35 & 73.5 & 6 & & 56.7 \\
\hline 18 & 25 & 22 & 10 & & 2.03 \\
\hline 19 & 45 & 73.5 & 6 & & 6.35 \\
\hline
\end{tabular}

\subsection{Phenol Adsorption Experiments}

Initially, phenol stock solution $1000 \mathrm{mg} / \mathrm{L}$ was prepared from which required concentrations for experimentation (20-125 mg/L) were prepared via serial dilution using Millipore machine filtered deionized water. For each test run under the conditions in 
Table 1, the phenol solution with a target concentration and $\mathrm{pH}$ set using $0.1 \mathrm{M} \mathrm{NaOH}$ or $0.1 \mathrm{M} \mathrm{HNO}_{3}$ was transferred to a $50 \mathrm{~mL}$ glass flask. The flask was firmly placed in an SK-600 Benchtop and then agitated at $120 \mathrm{rpm}$. Based on a preliminary investigation of the influence of dosage and time, a fixed dosage of $10 \mathrm{mg}$ and an equilibrium time of $180 \mathrm{~min}$ were used for all the RSM experiments. At the end of each test run, the supernatant water was immediately separated from the spent adsorbent, first by filtering through a 0.45 -micron filter, which was then followed by centrifuge separation operated for $5 \mathrm{~min}$ at $3500 \mathrm{rpm}$. The residual phenol concentration in each sample was determined using well-calibrated $\left(R^{2}>0.9998\right)$ HPLC (Thermo Scientific) UltiMate ${ }^{\mathrm{TM}} 3000$ and a photodiode array detector set at $270 \mathrm{~nm}$ wavelength.

\subsection{Adsorption Kinetics and Equilibrium}

The phenol uptake kinetics onto the SBAC-MgAlFe-LDH was investigated using four (4) different non-linear equations that included pseudo-first and pseudo-second-order [39], intraparticle diffusion and Elovich [40], and Avrami fractional-order [41] models. Meanwhile, to further comprehend the phenol interaction with the SBAC-MgAlFe surface and elucidate the uptake mechanism, Temkin [42], Freundlich [43], Redlich and Peterson [44], Langmuir [45], and Liu [46] equilibrium models were employed.

\section{Results and Discussion}

\subsection{Characterization of Prepared Adsorbent before and after Phenol Uptake}

The SBAC-MgAlFe-LDH clear FTIR spectrum peaks that are presented in Figure 1a indicate the abundance of surface functional groups of the ternary LDH spectrum before and after phenol uptake. The FTIR on the fresh composite exhibited peak of interlayers at $1370 \mathrm{~cm}^{-1}$ and $3404 \mathrm{~cm}^{-1}$ assigned nitrate anions $\left(\mathrm{NO}_{3}^{-}\right)$and hydroxyl groups $(\mathrm{OH})$ binding onto the metal ions of the $\mathrm{LDH}(\mathrm{Al}, \mathrm{Mg}$, or Fe) [47]. However, for the loaded SBACMgAlFe-LDH that was evidently indicated by the reduced $\left(\mathrm{NO}_{3}^{-}\right)$anions in the composite, the high and clearer intensity of the -OH groups was attributed to the existence of the higher content of the SBAC-MgAlFe-LDH in the resulting composite. Meanwhile, mixed metal oxides are indicated by the peaks located below $600 \mathrm{~cm}^{-1}$; the C-O-C group's presence is attributed to the peak observed at $1023 \mathrm{~cm}^{-1}$ [48]. The existence of these identified surface functional groups indicates the potential of the new adsorbent as a candidate material for organic compounds uptake from water. As phenol was removed from the aqueous phase, there was an obvious transformation of the fresh SBAC-MgAlFe-LDH prior to the absorption, suggesting a possible contribution of surface functionalities for the phenol uptake $[49,50]$.

The SBAC-MgAlFe-LDH diffraction peaks are displayed in Figure $1 \mathrm{~b}$. The peaks at $2 \theta$ values of $62.18^{\circ}, 57.42^{\circ}, 51.77^{\circ}, 43.04^{\circ}, 38.39^{\circ}, 35.28^{\circ}$, and $30.63^{\circ}$ are mainly attributed to the patterns of the nanoparticles [17]. The weak yet broad peak located at $11.23^{\circ}$ corresponds to the graphitic carbon of the SBAC index plan. The XRD results suggests effective integration of the MgAlFe-LDH with the SBAC, resulting in the excellent crystalline structure of the composite. The measured BET specific surface area of $320.58 \mathrm{~m}^{2} / \mathrm{g}$, pore volume $0.278 \mathrm{~cm}^{3} / \mathrm{g}$, and pore radius $17.32 \mathrm{~nm}$ (based on $\mathrm{BJH}$ ) for the composite SBAC-MgAlFe-LDH are a significant improvement over the values obtained for the SBAC alone as $254.3 \mathrm{~m}^{2} / \mathrm{g}, 0.14 \mathrm{~cm}^{3} / \mathrm{g}$, and $117.59 \mathrm{~nm}$. The $\mathrm{N}_{2}$ isotherm trend suggests a type-IV hysteresis loop (Figure 1c), while the pore size distribution (Figure 1d) establishes that the SBAC-MgAlFe-LDH composites are characterized as mesoporous. 

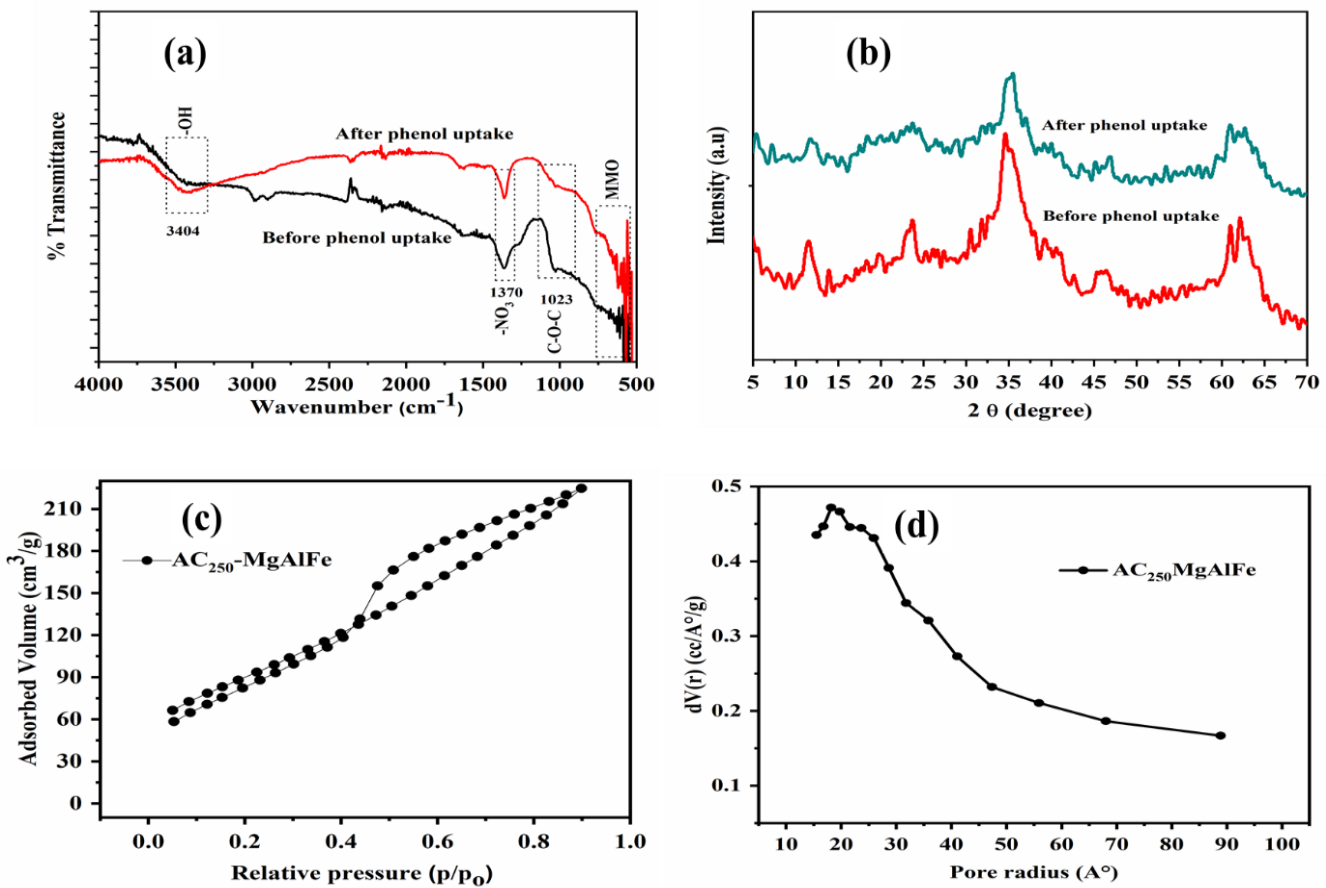

Figure 1. SBAC-MgAlFe characterization results: (a) XRD, (b) FTIR, (c) $\mathrm{N}_{2}$ adsorption-desorption isotherms, (d) pore size distribution.

The SEM photo depicted in Figure 2c implies a heterogeneous, highly porous, and rough surface morphology, agreeing with the XRD patterns (Figure 1b). Moreover, the TEM analysis in Figure 2a suggests that the SBAC-MgAlFe-LDH nanoparticles were uniformly and homogenously dispersed and framed within the interlayers of the MgAlFe-LDH with no indication of aggregation in the resulting composite, as required for LDH composites for enhancing required adsorptive characteristics of adsorbents. The EDS chemical composition analyses (Figure 2d) provided indicated the dominance of the chemical elements, $\mathrm{Fe}, \mathrm{Mg}$, and $\mathrm{Al}$, which forms the basis of the SBAC-MgAlFe-LDH. Thus, the observed improved physicochemical characteristics could be attributed to the uniform distribution of the SBAC nanoparticles into MgAlFe-LDH layers.
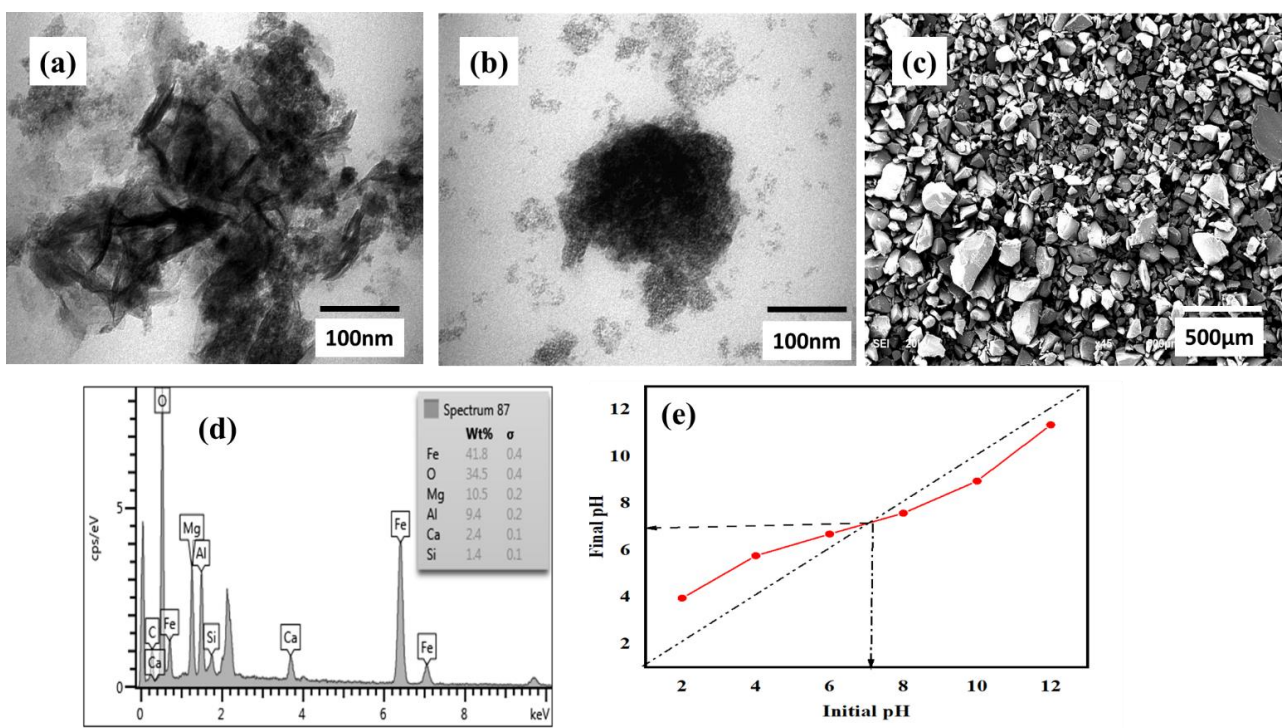

Figure 2. SBAC-MgAlFe: (a) TEM before phenol uptake, (b) TEM after phenol uptake, (c) SEM image, (d) EDS analyses, (e) Point of zero charge. 


\subsection{Development and Validation of RSM Model for Phenol Uptake}

The RSM regression model in Equation (1) was employed to fit in the obtained SBACMgAlFe-LDH phenol uptake data from which Equation (2) was obtained as the best-fitted model. The lower residuals, as provided in Table 1 and Figure $3 a$, indicate the closeness between the actual and model's predicted values which suggests the high prediction ability of the developed phenol uptake RSM model. This is further corroborated via considerations of the significance of the model's term and the insignificance of lack-offit (LOF); $p$-values $<0.0001$ and 0.5066 were established at $5 \%(p$-value $<0.05)$ (Table 2$)$, respectively [34]. The analysis of variance (ANOVA) presented in Table 2 also shows that the influence of all the investigated parameters was established as all their $p$-values are $<0.05[34,37]$. The developed model implies that the coded model's terms A, B, C, $C^{2}, A^{2} B$, and $A B^{2}$ are the primary significant model terms. Thus, the best phenol uptake model was a reduced cubic model that included only terms that significantly influence the model directly or indirectly. This means that some of the included terms, even though they are insignificant on their own, must be included as they are hierarchical terms that are indirectly reflected in higher terms that were found to significantly influence the model. In this case of the presented phenol uptake model, $A B$ and $A^{2}$ are insignificant; however, $A^{2} B$ and $A B^{2}$ are highly significant terms that greatly contributed to the final model quality. Accordingly, terms $\mathrm{AB}$ and $\mathrm{A}^{2}$ must be associated with the model as they contributed to the higher cubic terms that are significant; otherwise, if not included, the non-hierarchical coded model's predictions are more unlikely to match the actual model predictions [34].

$$
\begin{aligned}
\mathrm{q}_{\mathrm{e}}(\mathrm{mg} / \mathrm{g})= & +56.70+10.32 \mathrm{~A}+39.48 \mathrm{~B}-3.02 \mathrm{C}+0.48 \mathrm{AB}-0.87 \mathrm{AC}-1.24 \mathrm{BC}- \\
& 0.6644 \mathrm{~A}^{2}+1.44 \mathrm{~B}^{2}-49.32 \mathrm{C}^{2}-34.98 \mathrm{~A}^{2} \mathrm{~B}-9.14 \mathrm{AB}^{2}
\end{aligned}
$$
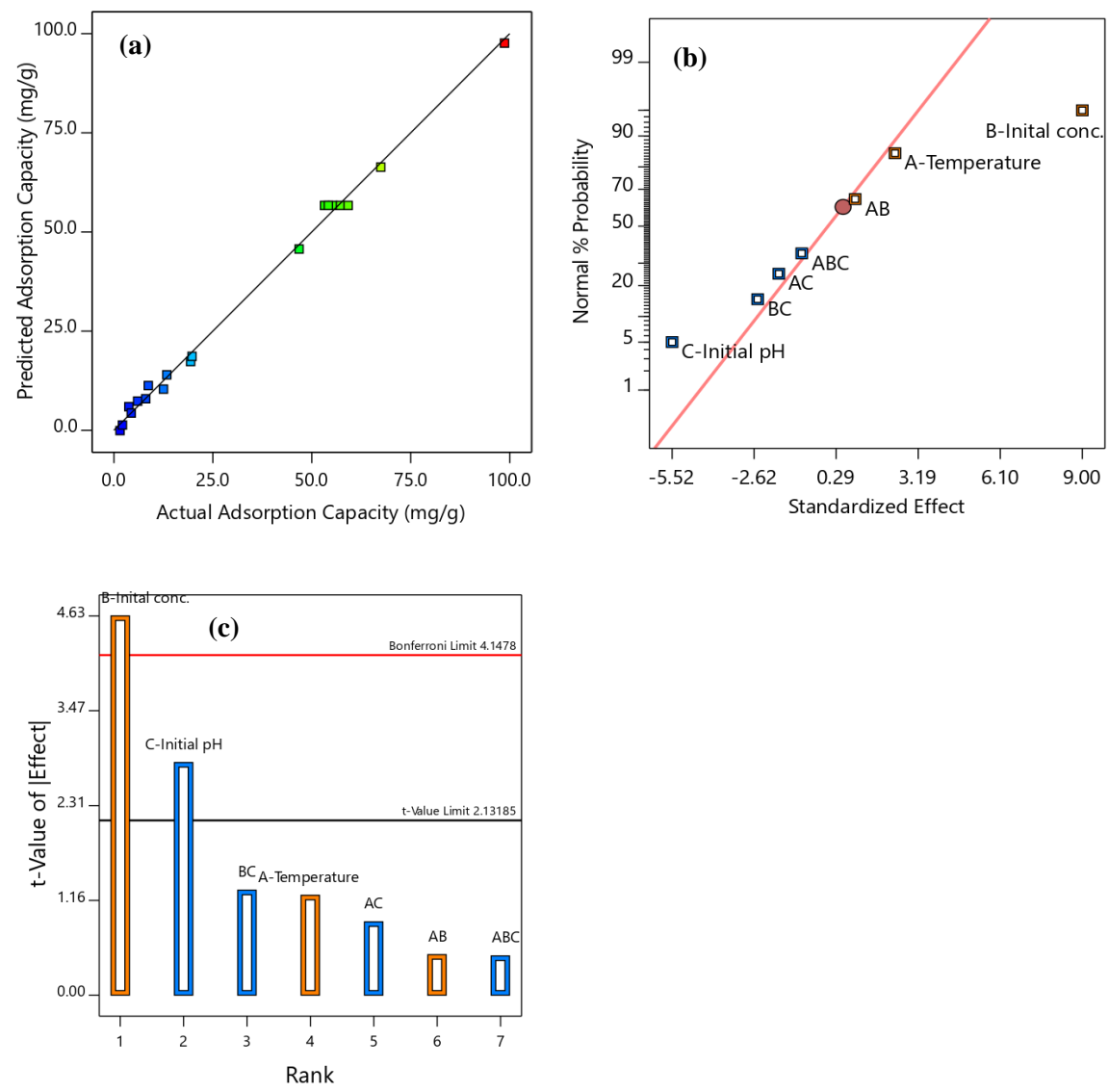

Figure 3. SBAC-MgAlFe-LDH adsorption capacity model's (a) Experimental (actual) versus predicted values, (b) Probability normal plot, (c) Pareto chart. 
Table 2. ANOVA for a reduced cubic model for SBAC-MgAlFe-LDH phenol adsorption capacity model.

\begin{tabular}{ccc}
\hline Variation Source & F-Value & $p$-Value \\
\hline Model & 243.92 & $<0.0001^{\mathrm{a}}$ \\
A-Temperature & 38.26 & $0.0005^{\mathrm{a}}$ \\
B-Initial conc. & 559.94 & $<0.0001^{\mathrm{a}}$ \\
C-Initial pH & 16.43 & $0.0049^{\mathrm{a}}$ \\
$\mathrm{AB}$ & 0.3311 & $0.5830^{\mathrm{b}}$ \\
$\mathrm{A}^{2}$ & 0.2166 & $0.6558^{\mathrm{b}}$ \\
$\mathrm{B}^{2}$ & 1.01 & $0.3480^{\mathrm{b}}$ \\
$\mathrm{C}^{2}$ & 1194.05 & $<0.0001^{\mathrm{a}}$ \\
$\mathrm{A}^{2} \mathrm{~B}$ & 351.66 & $<0.0001^{\mathrm{a}}$ \\
$\mathrm{AB}^{2}$ & 23.98 & $0.0018^{\mathrm{a}}$ \\
LOF & 0.9226 & $0.5066^{\mathrm{a}}$ \\
\hline $\mathrm{R}^{2}=0.9978 ;$ & $\mathrm{R}^{2}$-Adjusted $=0.993 ;$ & $\mathrm{R}^{2}$-Predicted $=0.959$
\end{tabular}

a Significance established at $5 \%(p$-value $<0.05) ;{ }^{\mathrm{b}}$ Significance established based on higher interaction effects ( $p$-value $<0.05) ;$ LOF $=$ Lack of fit.

In addition, the high predictive ability of the model is manifested in high values and closeness of the different coefficients of determination $R^{2}(0.998), R^{2}$-predicted (0.993), and $R^{2}$-adjusted (0.959) (as provided in Table 2). Thus, this implies that the values of both the biased and non-bias $\mathrm{R}^{2}$ and well the LOF are in conformity with one another, thereby meeting the requirements for RSM predictive models [51]. Meanwhile, the normal probability plot depicted in Figure $3 \mathrm{~b}$ implies that the model satisfied the assumption of normality. On the other hand, the linear model's normal probability plot shown in Figure 3b implies meeting the normality distribution assumption of the phenol uptake experimental data $[34,52,53]$. Similarly, the adequate precision of measures $51.149(>4)$ fulfilled the signalto-noise ratio requirements, and the $\mathrm{CV}=7.56 \%$ indicates the suitability and adequacy of the employability of the model for navigating the design space. Collectively, these checks imply that the developed phenol uptake model can adequately represent the experimental data obtained for evaluation, assessments, and drawing meaningful conclusions on phenol uptake by the SBAC-MgAlFe-LDH adsorbent.

\subsection{Influence of Operating Parameters on SBAC-MgAlFe-LDH Phenol Uptake}

The influence of SBAC-MgAlFe-LDH dosage and adsorption time is depicted in Figures $2 \mathrm{e}$ and $3 \mathrm{a}$, respectively. These results $(10-25 \mathrm{mg} / \mathrm{L})$ indicated that as the dosage was increased, the adsorption capacity decreased. Meanwhile, at $10 \mathrm{mg}$ dosage, increasing the time yielded higher capacity for phenol uptake, which equilibrated at $180 \mathrm{mg} / \mathrm{L}$. As a result, the dosage of $10 \mathrm{mg}$ and reaction time of $180 \mathrm{~min}$ were used for all RSM experiments.

The influences of the operational conditions (temperature, initial phenol concentration, and $\mathrm{pH}$ ) on the performance of SBAC-MgAlFe-LDH for phenol uptake are presented in the Pareto chart (Figure 3b), and the contours and 3D plots are presented in Figure 4a-c. The Pareto chart depicts visual comparative hierarchical contributions of the single, binary and higher interactions of the RSM model's parameters on the phenol uptake capacity. The higher the Pareto chart's bar, the higher the relative contribution of an investigated parameter on the model's performance, [34,52]. Hence, parameter B (initial concentration) has the strongest influence, which is followed by factor $\mathrm{C}$ (initial $\mathrm{pH}$ ). 
(a)

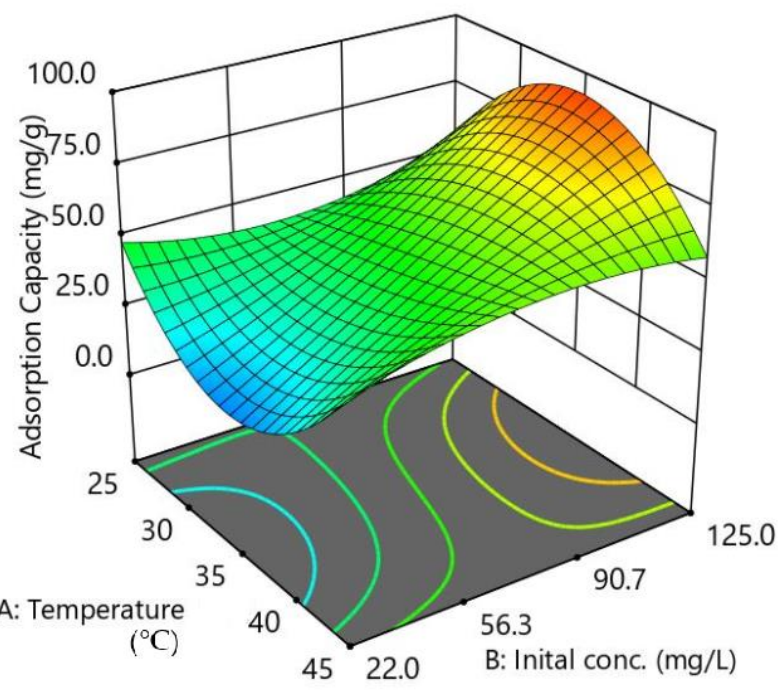

(b)

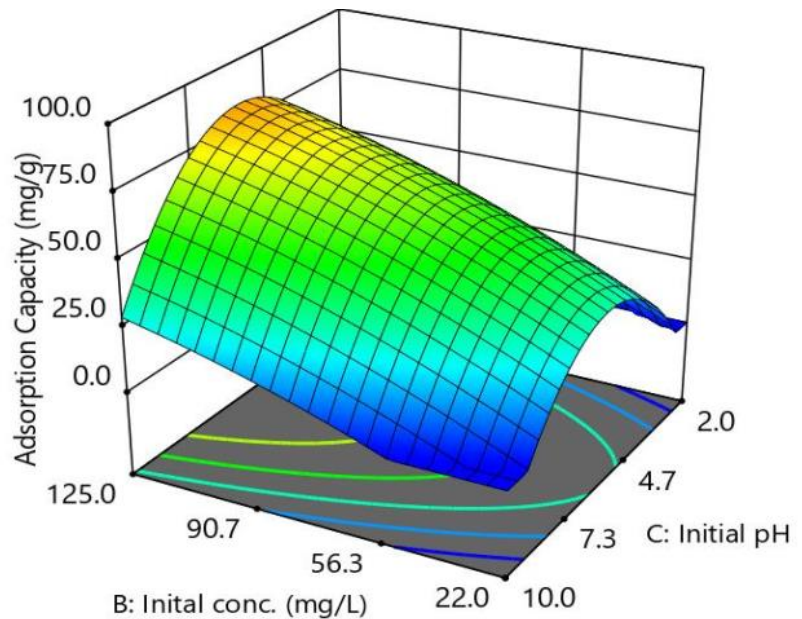

(c)

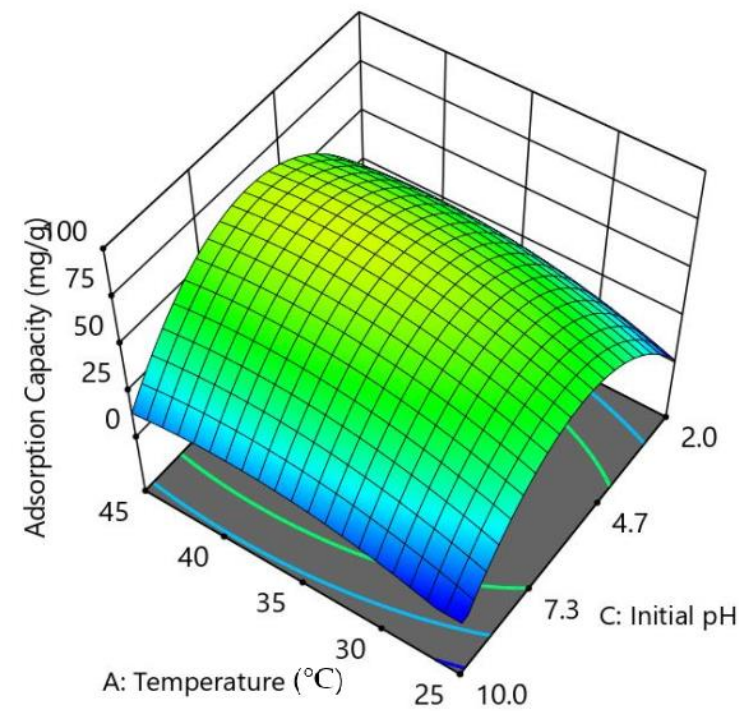

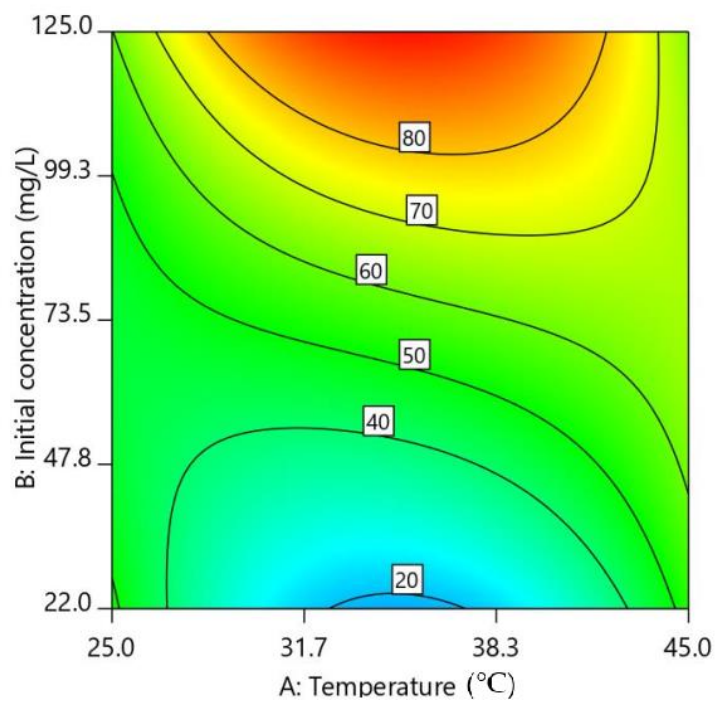
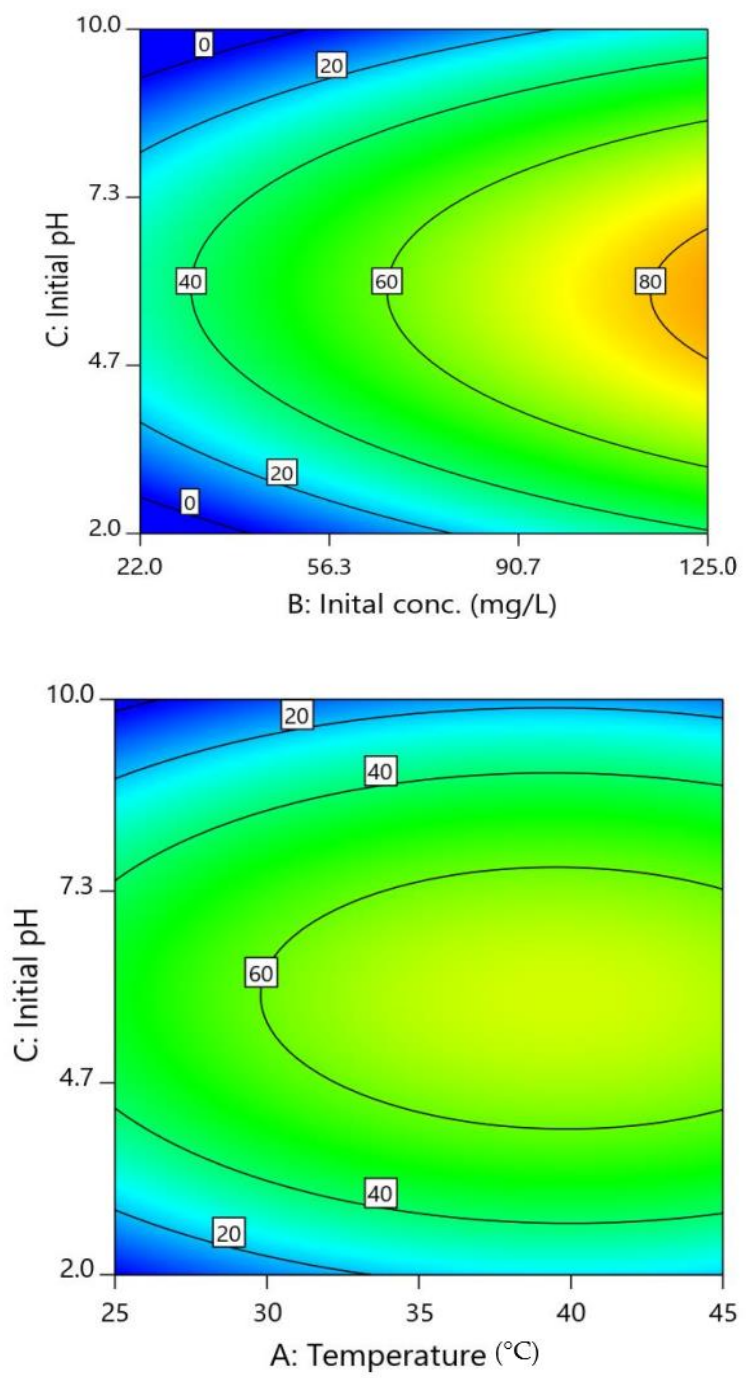

Figure 4. Effect of (a) Temperature vs. initial concentration at fixed pH 6, (b) Initial concentration vs. initial pH, (c) Temperature vs. initial $\mathrm{pH}$ on SBAC-MgAlFe capacity for phenol uptake.

Meanwhile, the influence of the interaction effects follows the order $B C>A B>A B$. This shows that parameters $\mathrm{B}$ and $\mathrm{C}$ are the major influencing factors outweighing temperature 
(A), whose influence was less, comparatively. Moreover, the Pareto chart shows that factors $\mathrm{A}, \mathrm{B}$, and $\mathrm{AB}$ (orange bar) and factors $\mathrm{C}, \mathrm{BC}$, and $\mathrm{AC}$ (blue bars) have an antagonistic and synergetic influence on the SBAC-MgAlFe-LDH adsorption capacity, respectively, which dependently corroborates the ANOVA analyses as well as the developed model's terms coefficients (Equation (1)). The Pareto chart t-test cut line indicated that besides the normal $t$-test $(t=1.367)$, the more conservative Bonferroni correction limit $(t=2.92)$ further establishes the stronger influences of initial concentration and initial $\mathrm{pH}$ on phenol uptake by the SBAC-MgAlFe-LDH [34,52].

The 3D curves and two-counter plots provided in Figure 4a-c depict visual influences of changing of the two parameters investigated on $\mathrm{q}_{\mathrm{e}}$ while the other factor was fixed. At the fixed lowest initial pH 2 and when the initial concentration was at the lowest level, the obtainable $\mathrm{q}_{\mathrm{e}}$ was the lowest $(1.56-6.00 \mathrm{mg} / \mathrm{g}$ ) and was not significantly affected by temperature changes (Table 2). However, at $\mathrm{pH} 6$ (Figure 4a), temperature (A) and initial concentration (B) greatly influenced the $\mathrm{q}_{\mathrm{e}}$ value, which resulted in the highest obtainable capacity of $98.7 \mathrm{mg} / \mathrm{g}$ at the highest phenol concentration of $125 \mathrm{mg} / \mathrm{L}$ phenol and midlevel temperature of $35^{\circ} \mathrm{C}$. Figure $4 \mathrm{a}$ implies that the best performances of the adsorbent at the lowest investigated phenol concentration $\left(\mathrm{q}_{\mathrm{e}}=50 \mathrm{mg} / \mathrm{g}\right)$ was achievable at $\mathrm{pH} 6$ and $25^{\circ} \mathrm{C}$ (or $45^{\circ} \mathrm{C}$ ), while at the mid-value temperature of $35^{\circ} \mathrm{C}$, the $\mathrm{q}_{\mathrm{e}}$ drastically dwindled to the low value. Meanwhile, Figure $4 \mathrm{~b}$ depicts the stronger influence of interaction between factors $B$ and $C$, which clearly shows the direct positive direct dependency of the $\mathrm{q}_{\mathrm{e}}$ on initial phenol concentration with the best performance attached at $125 \mathrm{mg} / \mathrm{L}$ phenol concentration, confirming the earlier observation. On the other hand, as the $\mathrm{pH}$ was raised from 2, the performance climax was achieved when it reached the value of 6 before it started decreasing and returning to the initial lower value at $\mathrm{pH} 10$. Moreover, at a fixed initial phenol concentration of $73.5 \mathrm{mg} / \mathrm{L}$, Figure $4 \mathrm{c}$ further reaffirms the stronger curvature influence of initial $\mathrm{pH}$ (the higher model's $\mathrm{C}^{2}$ coefficient) as a result of interaction with the temperature at a fixed initial concentration. Figure $4 \mathrm{c}$ also revealed the stronger influence of initial $\mathrm{pH}$ compared to the temperature, which exerted less effect, and it also showed that the optimal $\mathrm{pH}$ was $\mathrm{pH}$ 6. These trends clearly corroborated the Pareto chart (Figure 3c), which suggests higher relative contributions of factors $B$ and $C$ on the adsorptive performance of the SBAC-MgAlFe-LDH compared to factor A. Thus, jointly, Figures $3 \mathrm{~b}, \mathrm{c}$ and 4 , and ANOVA (Table 2) show that temperature variation evidently exerted a lower influence on the LDH phenol adsorptive performance compared to initial $\mathrm{pH}$ and initial phenol concentrations. For the best performance of the SBAC-MgAlFe-LDH for phenol uptake, the values of factors $C, B$, and A should be preferably at $6,125 \mathrm{mg} / \mathrm{L}$, and $35^{\circ} \mathrm{C}$, respectively.

The $\mathrm{q}_{\mathrm{e}}$ enhancement as a result of an increase in initial phenol concentration was ascribed to an improved induction of more contacts among phenol molecules and the active SBAC-MgAlFe-LDH sites possessing abundant functional groups as more phenol particles were introduced in the aqueous phase solution [54].

The dependencies of the SBAC-MgAlFe-LDH phenol uptake capacity changes with initial $\mathrm{pH}$ can be deduced based on the phenol speciation and surface charge of the SBACMgAlFe-LD. Thus, the results of the drift method employed to determine the point of zero charge $\left(\mathrm{pH}_{\mathrm{pzc}}\right)$ of the $\mathrm{SBAC}-\mathrm{MgAlFe}-\mathrm{LDH}$ suggest a $\mathrm{pH}_{\mathrm{pzc}}=7.09$ (Figure 2e). Accordingly, this result implies that when the $\mathrm{pH}$ was below the neutral point, the charges on the SBAC-MgAlFe-LDH surface becomes positive due to protonation, which implies stronger electrostatic repulsion between phenol molecules and the surface of the SBAC-MgAlFeLDH composite, which resulted in lower $\mathrm{q}_{\mathrm{e}}[17,25]$. However, at $\mathrm{pH} 6$, which is closer to the $\mathrm{pH}_{\mathrm{pzc}}$, a significant reduction in the positive charge on the surface of the adsorbent could be attributed to the higher performance of the SBAC-MgAlFe-LDH at the mid-value $\mathrm{pH}$, as observed earlier.

Meanwhile, as the $\mathrm{pH}$ was increased beyond 6, the gradual transformation of the active SBAC-MgAlFe-LDH sites to negative charge might have induced repulsive electrostatic forces between phenol molecules and the LDH sites, thus leading to the observed 
decreased in the $\mathrm{q}_{\mathrm{e}}$. Similar behavior for phenol uptake dependency on initial $\mathrm{pH}$ has been reported earlier [17]. The results indicated that electrostatic attraction is not associated to phenol uptake onto an SBAC-MgAlFe LDH composite. Interestingly, higher phenol uptake at $\mathrm{pH} 6$ is mainly associated to a lower protonated surface, which allows phenol molecules to easily interact with composite surface functional groups $(\mathrm{OH}, \mathrm{MMO}$, and C-O-C) [20,55]. Generally, the good $\mathrm{q}_{\mathrm{e}}$ at the best operational conditions was attributed to the successful intercalation of SBAC onto the interlayers of MgALFe-LDH, thereby improving its adsorptive characteristics.

\subsection{RSM Optimization}

Numerical optimization has been an indispensable tool for multivariate problems $[34,56]$. This is due to the intricacies associated with the identification of optimal operational points, which necessitated the simultaneous examination of all independent and dependent variables data. Consequently, optimization for SBAC-MgAlFe-LDH phenol uptake was performed under different operational conditions using the Design-Expert ${ }^{\circledR}$ software numerical optimization function, which is called the "desirability function". Thus, the desirability function capabilities were implemented under five (5) different scenarios, as presented in Table 3. According to the respective scenarios' target goals and constraints (collectively), the well-defined and strong desirability algorithm that navigates the data finds the best solution(s) and ranks them according to the value of the "desirability" parameter that is between 1 and 0 , which are designated as best to worst solutions in satisfying the optimization criteria and target goals. Accordingly, the maximum phenol uptake was set as the targeted objectives, while a variety of objectives and constraints for operating are targeted for the five (5) different scenarios 1 to 5 (Table 3). The results for the different scenarios suggest that higher initial phenol concentration and mid-value $\mathrm{pH}$ provide a higher desirability of the optimal solution and thus the best uptake capacity. Meanwhile, for lower initial phenol concentrations, the temperature has minimal influence on the achievable phenol uptake capacity. Thus, the highest uptake capacity obtained is inconsistent with the developed RSM model analyses presented earlier with the condition of optimality selected as $\mathrm{A}=35^{\circ} \mathrm{C}, \mathrm{B}=125 \mathrm{mg} / \mathrm{L}$, and $\mathrm{C}=6$, which is employed for understanding mechanisms of phenol uptake onto SBAC-MgAlFe-LDH via equilibrium and kinetics studies.

Table 3. RSM predicted numerical optimization scenarios result for SBAC-MgAlFe-LDH phenol uptake.

\begin{tabular}{ccccccccccccc}
\hline \multirow{2}{*}{$\begin{array}{c}\text { Operational } \\
\text { Parameter }\end{array}$} & \multicolumn{4}{c}{ Target Goals for Each Scenario } & \multicolumn{5}{c}{ Scenario Optimization Results } \\
\cline { 2 - 12 } & $\mathbf{1}$ & $\mathbf{2}$ & $\mathbf{3}$ & $\mathbf{4}$ & $\mathbf{5}$ & $\mathbf{1}$ & $\mathbf{2}$ & $\mathbf{3}$ & $\mathbf{4}$ & $\mathbf{5}$ \\
\hline $\mathrm{A}$ & In range & minimize & minimize & minimize & In range & 45 & 25 & 25 & 28.5 & 35 \\
\hline $\mathrm{B}$ & 22.4 & 22.4 & 73.7 & 125 & In range & 22.5 & 22.4 & 73.7 & 125 & 125 \\
\hline $\mathrm{C}$ & In range & In range & In range & In range & In range & 5.89 & 5.963 & 5.91 & 5.848 & 5.82 \\
\hline $\begin{array}{c}\text { Phenol Uptake, } \\
\text { qe, mg/g }\end{array}$ & maximize & maximize & maximize & maximize & maximize & 53.91 & 52.138 & 45.731 & 81.831 & 97.728 \\
\hline Desirability & - & - & - & - & - & 0.539 & 0.722 & 0.674 & 0.824 & 0.990 \\
\hline
\end{tabular}

\subsection{Adsorption Kinetics and Equilibrium Studies}

Kinetics of phenol uptake onto the SBAC-MgAlFe-LDH was studied using five (5) non-linear forms of popular kinetic models [39-41,57]. The kinetic models' fittings against the experimental values of the four (4) best fitted models are displayed in Figure 5, while the respective models' parameters are provided in Table 4 . Considering the higher $R^{2}=0.98$ and lower RMSE $=2.706$ for the pseudo-first-order model implies that the kinetics of phenol uptake onto the SBAC-MgAlFe-LDH can be explained by the pseudo-first-order model. Interestingly, the Avrami model performance and model's parameters match that of the first order (Table 4), reaffirming the first-order model's better representation of the experimental data and its suitability for providing insight into the phenol uptake kinetics. 


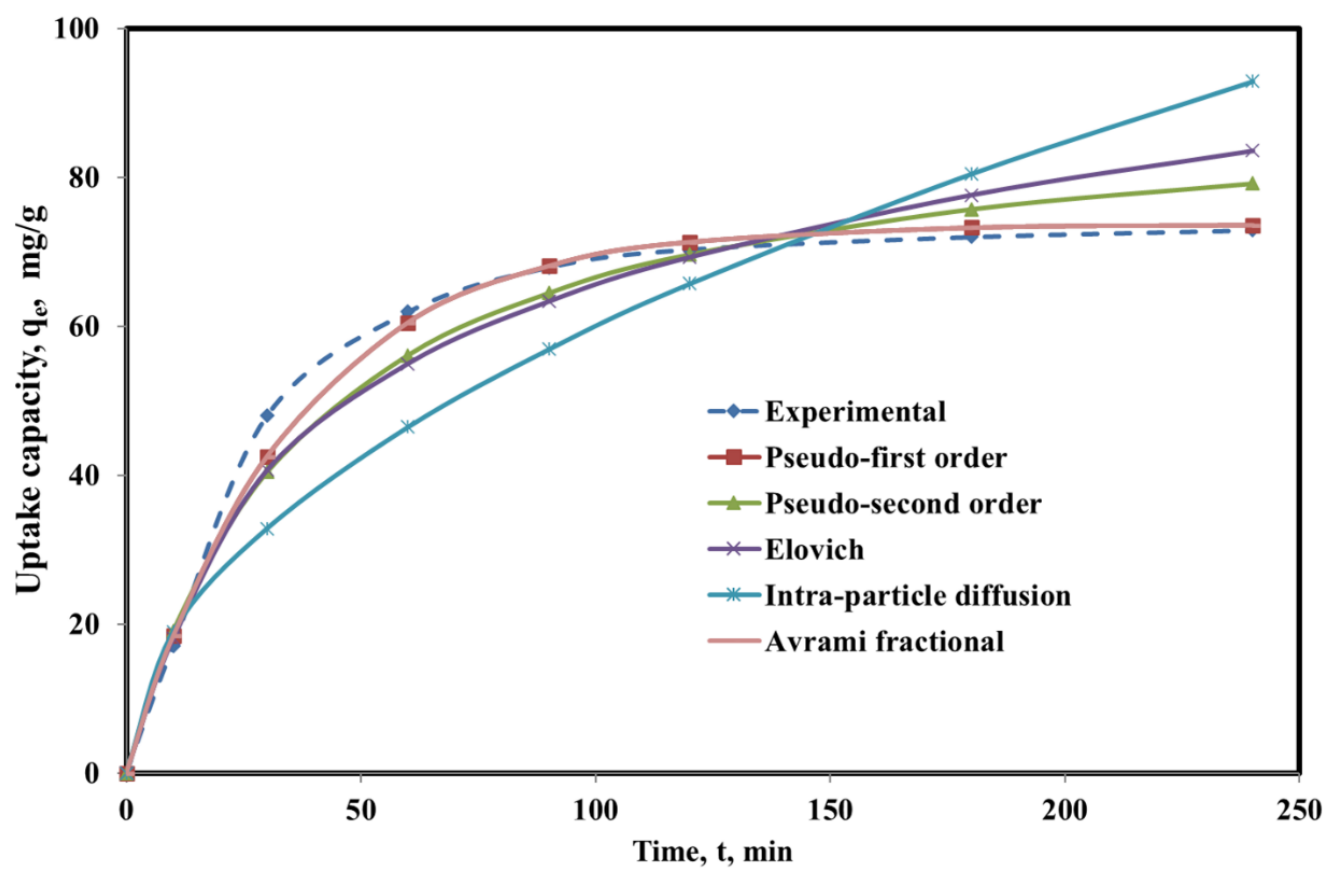

Figure 5. Plots for experimental data vs. predictions for non-linear kinetic models for SBAC-MgAlFe phenol uptake.

Table 4. Parameters for different non-linear kinetic model fittings under the optimal conditions.

\begin{tabular}{|c|c|c|c|}
\hline Model & $\begin{array}{l}\text { Mathematical } \\
\text { Representation }\end{array}$ & Parameter & Value \\
\hline \multirow{4}{*}{ Pseudo-First Order } & \multirow{4}{*}{$\mathrm{q}_{\mathrm{t}}=\left(1+\mathrm{e}^{-\mathrm{k}_{1} \mathrm{t}}\right)$} & $\mathrm{q}_{\mathrm{e}}(\mathrm{mg} / \mathrm{g})$ & 73.65 \\
\hline & & $\mathrm{k}_{1}$ & 0.0287 \\
\hline & & $\mathrm{R}^{2}$ & 0.980 \\
\hline & & RMSE & 2.706 \\
\hline \multirow{4}{*}{ Pseudo-Second Order } & \multirow{4}{*}{$\mathrm{q}_{\mathrm{t}}=\frac{\mathrm{q}_{\mathrm{e}}^{2} \mathrm{k}_{2} \mathrm{t}}{1+\mathrm{q}_{\mathrm{e}} \mathrm{k}_{2} \mathrm{t}}$} & $\mathrm{q}_{\mathrm{e}}(\mathrm{mg} / \mathrm{g})$ & 91.7331 \\
\hline & & $\mathrm{k}_{2}$ & 0.0003 \\
\hline & & $\mathrm{R}^{2}$ & 0.9401 \\
\hline & & RMSE & 5.6701 \\
\hline \multirow{4}{*}{ Elovich } & \multirow{4}{*}{$\mathrm{q}_{\mathrm{t}}=\frac{1}{\beta} \ln (\alpha \beta \mathrm{t})$} & $\alpha$ & 4.9400 \\
\hline & & $\beta$ & 0.0485 \\
\hline & & $\mathrm{R}^{2}$ & 0.9290 \\
\hline & & RMSE & 125.2419 \\
\hline \multirow{4}{*}{$\begin{array}{l}\text { Intra-Particle } \\
\text { Diffusion }\end{array}$} & \multirow{4}{*}{$q_{t}=k_{d} t^{1 / 2}+C$} & $\mathrm{~K}_{\mathrm{d}}$ & 5.9960 \\
\hline & & $\mathrm{C}$ & 0.0009 \\
\hline & & $\mathrm{R}^{2}$ & 0.7063 \\
\hline & & RMSE & 11.6561 \\
\hline \multirow{5}{*}{ Avrami Fractional } & \multirow{5}{*}{$\mathrm{q}_{\mathrm{e}}=\mathrm{q}_{\max }\left[\left(1-\exp \left(\mathrm{K}_{\mathrm{av}} \mathrm{t}\right)\right]^{\mathrm{n}}\right.$} & $\mathrm{q}_{\mathrm{e}}$ & 73.65 \\
\hline & & $\mathrm{K}_{\mathrm{av}}$ & 0.0379 \\
\hline & & $\mathrm{n}$ & 0.758 \\
\hline & & $\mathrm{R}^{2}$ & 0.980 \\
\hline & & RSME & 2.717 \\
\hline
\end{tabular}

To further elucidate the phenol uptake mechanism under equilibrium conditions and determine the maximum uptake capacity of phenol onto the SBAC-MgAlFe-LDH, non-linear forms of the five (5) different popular equilibrium models were employed in this study $[35,58]$. The fittings of these isotherm models are depicted in Figure 6, while their corresponding models' parameters obtained are presented in Table 5. In terms of $R^{2}$ and RMSE, the predictive performance of these models follows the order: Liu > Redlich- 
Peterson $>$ Langmuir $>$ Freundlich $>$ Tempkin. The Liu and Redlich-Peterson models represent a combination of Langmuir and Freundlich models distinctly at either higher or lower concentration. This analysis implies that SBAC-MgAlFe-LDH phenol uptake can be satisfactorily explained by Liu $\left(R^{2}=0.996\right.$ and RMSE $\left.=1.67\right)$ [46], Langmuir $\left(R^{2}=0.995\right.$ and RMSE = 1.91), and Redlich-Peterson $\left(R^{2}=0.995\right.$ and RMSE $\left.=1.91\right)$ [44]. The better fittings for the Liu [46] and Redlich-Peterson [44] models are in line with earlier findings for phenolic compounds uptake by SBAC [22]. The maximum achievable monolayer phenol uptake capacity $\left(\mathrm{q}_{\max }\right)$ for SBAC-MgAlFe-LDH as per the Langmuir model was estimated at 216.76 (Table 5), even though Figure 6 indicates that the adsorption isotherms are not complete and were just reaching the maximum adsorption capacity.

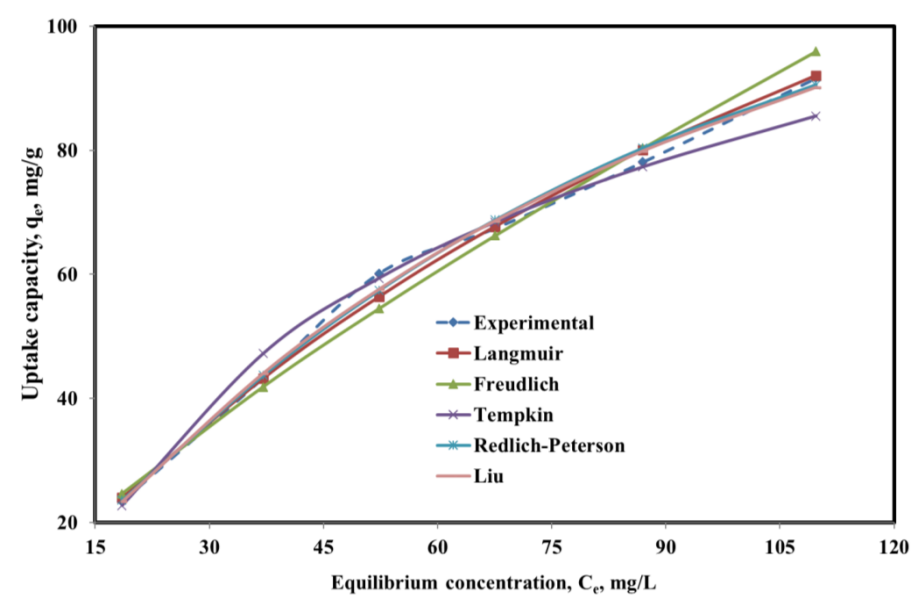

Figure 6. Plots for experimental data vs. predictions for non-linear equilibrium models for SBACMgAlFe phenol uptake.

Table 5. Parameters for different non-linear equilibrium models under the optimal conditions.

\begin{tabular}{|c|c|c|c|}
\hline Model & $\begin{array}{l}\text { Mathematical } \\
\text { Representation }\end{array}$ & Parameter & Value \\
\hline Langmuir & $\mathrm{q}_{\mathrm{e}}=\frac{\mathrm{q}_{\max } \cdot \mathrm{K}_{\mathrm{L}} \cdot \mathrm{C}_{\mathrm{e}}}{1+\mathrm{K}_{\mathrm{L}} \cdot \mathrm{C}_{\mathrm{e}}}$ & $\begin{array}{c}\mathrm{q}_{\max ,(\mathrm{mg} / \mathrm{g})} \\
\mathrm{K}_{\mathrm{L}} \\
\mathrm{R}^{2} \\
\text { RMSE }\end{array}$ & $\begin{array}{l}216.76 \\
0.0067 \\
0.9976 \\
1.9100\end{array}$ \\
\hline Freundlich & $\mathrm{q}_{\mathrm{e}}=\mathrm{K}_{\mathrm{F}} \mathrm{C}_{\mathrm{e}^{\frac{1}{n}}}$ & $\begin{array}{c}\mathrm{K}_{\mathrm{F}} \\
1 / \mathrm{n} \\
\mathrm{R}^{2} \\
\text { RMSE }\end{array}$ & $\begin{array}{l}2.6567 \\
0.7635 \\
0.9867 \\
2.9146\end{array}$ \\
\hline Tempkin & $\mathrm{q}_{\mathrm{e}}=\mathrm{B} \cdot \ln \left(\mathrm{A} \cdot \mathrm{C}_{\mathrm{e}}\right)$ & $\begin{array}{c}\text { A } \\
\text { B } \\
\mathrm{R}^{2} \\
\text { RMSE }\end{array}$ & $\begin{array}{c}0.1030 \\
35.2738 \\
0.9832 \\
0.0041\end{array}$ \\
\hline Redlich-Peterson & $\mathrm{q}_{\mathrm{e}}=\frac{\mathrm{K}_{\mathrm{R}} \cdot \mathrm{C}_{\mathrm{e}}}{1+\mathrm{a}_{\mathrm{R}} \mathrm{C}_{\mathrm{e}}^{\mathrm{G}}}$ & $\begin{array}{c}\mathrm{K}_{\mathrm{R}} \\
\mathrm{a}_{\mathrm{R}} \\
\mathrm{G} \\
\mathrm{R}^{2} \\
\mathrm{RMSE}\end{array}$ & $\begin{array}{c}1.458 \\
0.0009 \\
0.989 \\
0.9948 \\
1.910\end{array}$ \\
\hline Liu & $\mathrm{q}_{\mathrm{e}}=\frac{\mathrm{q}_{\max } \cdot\left(\mathrm{K}_{\mathrm{g}} \cdot \mathrm{C}_{\mathrm{e}}\right)^{\mathrm{n}_{\mathrm{L}}}}{1+\left(\mathrm{K}_{\mathrm{g}} \cdot \mathrm{C}_{\mathrm{e}}\right)^{\mathrm{n}_{\mathrm{L}}}}$ & $\begin{array}{c}\mathrm{qmax}_{\max } \\
\mathrm{K}_{\mathrm{g}} \\
\mathrm{n}_{\mathrm{L}} \\
\mathrm{R}^{2} \\
\mathrm{RMSE}\end{array}$ & $\begin{array}{c}153.94 \\
0.01227 \\
1.1602 \\
0.996 \\
1.670\end{array}$ \\
\hline
\end{tabular}


A comparison of SBAC-MgAlFe-LDH phenol uptake capacity with other sewage sludgebased adsorbents produced using different activation methods is provided in Table 6 . The ternary SBAC-MgAlFe-LDH reported herein possessing $216.76 \mathrm{mg} / \mathrm{g}$ capacity for phenol sorption implies an effective composite material for the effective removal of phenol from water. This is a significant improvement over SBAC reported capacities using conventional heating $=34.36 \mathrm{mg} / \mathrm{g}$ and microwave [22] and activation using $\mathrm{CO}_{2}=32.4 \mathrm{mg} / \mathrm{g}$ [23]; chemical agents such as $\mathrm{ZnCl}_{2}=20.95-81.6 \mathrm{mg} / \mathrm{g}$ [24,25], citric acid $-\mathrm{ZnCl}_{2}$ mixture [26] = $2.01 \mathrm{mmol} / \mathrm{g}$, $\mathrm{NaOH}=17.82-96.15 \mathrm{mg} / \mathrm{g}[25,27], \mathrm{H}_{2} \mathrm{SO}_{4}=26.16 \mathrm{mg} / \mathrm{g}$ [28], polymer flocculants = 132.33 [29], and $\mathrm{ZnCl}_{2}$-activated SBAC-MgFe-LDH $=138.69 \mathrm{mg} / \mathrm{g}$ [17]. Thus, the high uptake capacity exhibited by the $\mathrm{NaOH}$ SBAC-LDH reported in this study was ascribed to the successful synergistic influence of SBAC and the MgAlFe-based LDH composite, which yielded improved and abundant surface functional groups that supported the adsorption of more phenol molecules from water.

Table 6. Comparison of SBAC-MgAlFe-LDH phenol uptake capacity with other sewage sludge-based adsorbents produced using different activation methods.

\begin{tabular}{|c|c|c|c|c|c|c|c|}
\hline \multirow{2}{*}{$\begin{array}{c}\text { SBAC } \\
\text { Type/Activation } \\
\text { Agent }\end{array}$} & \multirow{2}{*}{$\begin{array}{c}\text { Uptake Capacity } \\
\text { (mg/g) }\end{array}$} & \multicolumn{5}{|c|}{ Operational Conditions } & \multirow[b]{2}{*}{ Reference } \\
\hline & & $\begin{array}{l}\text { Initial Conc. } \\
(\mathrm{mg} / \mathrm{L})\end{array}$ & $\mathrm{pH}$ & Dosage (mg) & Temp $\left({ }^{\circ} \mathrm{C}\right)$ & Time (min) & \\
\hline $\mathrm{ZnCl}_{2}-\mathrm{SBAC}$ & 20.95 & 60 & 8 & 100 & 25 & 360 & [25] \\
\hline $\mathrm{NaOH}-\mathrm{SBAC}$ & 17.82 & 60 & 8 & 100 & 25 & 360 & [25] \\
\hline $\begin{array}{c}\mathrm{ZnCl}_{2} \text {-SBAC- } \\
\mathrm{MgFe}-\mathrm{LDH}\end{array}$ & 138.69 & 100 & 6 & 10 & 25 & 180 & [17] \\
\hline $\begin{array}{l}\text { NaOH-SBAC- } \\
\text { MgAlFe-LDH }\end{array}$ & 216.76 & 100 & 6 & 10 & 35 & 125 & This study \\
\hline $\begin{array}{l}\text { Conventional } \\
\text { furnace activated } \\
\text { SBAC }\end{array}$ & 34.36 & 200 & - & 30 & 25 & 120 & [22] \\
\hline $\begin{array}{l}\text { Microwave- } \\
\text { activated } \\
\text { SBAC }\end{array}$ & 32.96 & 200 & - & 30 & 25 & 120 & [22] \\
\hline $\begin{array}{l}\mathrm{CO}_{2} \text {-activated } \\
\text { sludge }\end{array}$ & 32.4 & 250 & 5 & 15 & 20 & $72 \mathrm{~h}$ & [23] \\
\hline $\mathrm{H}_{2} \mathrm{SO}_{4} \mathrm{SBAC}$ & 26.16 & 200 & - & $5 \mathrm{~g} / \mathrm{L}$ & 20 & 120 & [28] \\
\hline $\begin{array}{c}\text { Citric } \\
\text { acid-ZnCl }{ }_{2} \text {-SBAC }\end{array}$ & 189.16 & $\begin{array}{l}0.5 \text { to } \\
50 \mathrm{mmol}\end{array}$ & 4 & $1 \mathrm{~g} / \mathrm{L}$ & 30 & $6 \mathrm{~h}$ & [26] \\
\hline $\mathrm{NaOH}-\mathrm{SBAC}$ & 96.15 & - & - & 10 & 25 & 60 & [27] \\
\hline $\mathrm{ZnCl}_{2}-\mathrm{SBAC}$ & 81.6 & 2000 & - & $1 \mathrm{~g} / 100 \mathrm{~mL}$ & 25 & $48 \mathrm{~h}$ & [24] \\
\hline $\begin{array}{c}\text { Polymer } \\
\text { flocculants } \\
\text { activated SBAC }\end{array}$ & 132.33 & 75 & 5 & - & 40 & - & [29] \\
\hline
\end{tabular}

\subsection{Thermodynamics and Regeneration Studies of SBAC-MgAlFe-LDH Composite}

At different experiment temperatures, 25,35 , and $45^{\circ} \mathrm{C}$, and fixed other conditions as per the optimal RSM conditions of initial phenol concentration of $125 \mathrm{mg} / \mathrm{L}$ and $\mathrm{pH} 6$, the thermodynamics of SBAC-MgAlFe-LDH composite phenol uptake were undertaken. At the respective different temperatures, the Gibbs free $\Delta \mathrm{G}^{\circ}$ values are close to each other with values of $-5.33,-5.53$ and $-5.77 \mathrm{~kJ} / \mathrm{mol}$, respectively, yielding an energy enthalpy $\Delta \mathrm{H}=16.52(\mathrm{~kJ} / \mathrm{mol})$ and entropy change $\Delta \mathrm{S}=-0.105(\mathrm{~kJ} / \mathrm{mol})$ obtained based on plotting the $\Delta \mathrm{G}^{\circ}$ values against the respective temperatures. The obtained parameters are given in Figure $7 \mathrm{a}$. In general, the $\Delta \mathrm{G}^{\circ}$ value that is in the range of 0 to $-20 \mathrm{~kJ} / \mathrm{mol}$ corresponds to physical adsorption $[59,60]$. Moreover, the value of the $\Delta \mathrm{H}$ is within the range of 2.1-20.9 $\mathrm{kJ} \mathrm{mol}^{-1}$, which further establishes the physical nature of phenol uptake by SBAC-MgAlFe-LDH. All the $\Delta \mathrm{G}^{\circ}$ values are negative, indicating the spontaneous and favorable nature of the phenol uptake by the SBAC-MgAlFe-LDH composite $[59,60]$. Additionally, as the temperature was raised, there was an observed drop in the $\Delta \mathrm{G}^{\circ}$ values. Meanwhile, there was also positive $+\Delta \mathrm{H}$ and absolute lower $\Delta \mathrm{G}^{\circ}(<20 \mathrm{~kJ} / \mathrm{mol})$, implying the endothermic nature of the phenol uptake. 

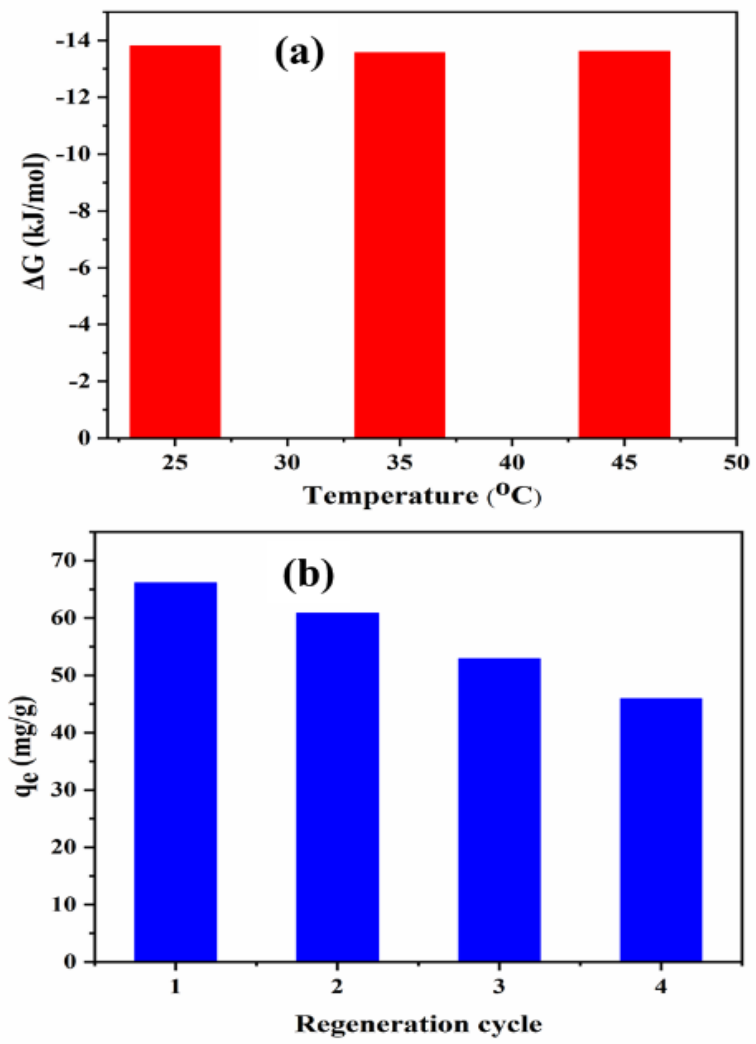

Figure 7. (a) Thermodynamic coefficients and (b) Consecutive regeneration and reusing of SBACMgAlFe for phenol uptake.

The regeneration of the SBAC-MgAlFe-LDH for phenol uptake was conducted for consecutive recycles adsorption onto the SBAC-MgAlFe-LDH and subsequent desorption using ethanol (95\% solution). The detailed procedure adopted to achieve this part has been reported elsewhere [17]. The result presented in Figure $7 \mathrm{~b}$ shows that the initial phenol uptake capacity for the fresh adsorbent of $66.12 \mathrm{mg} / \mathrm{g}$ decreased to $60.81,52.88$, and $45.88 \mathrm{mg} / \mathrm{g}$ after the first, second, and third regeneration and recycling. This is about $8.03 \%$, $20.02 \%$, and $30.611 \%$ of the original capacity, indicating the higher reusability potential of the SBAC-MgAlFe-LDH compared with the original capacities of similar adsorbents (Table 6).

\subsection{Possible Mechanisms of Phenol Uptake}

The synergetic effects of SBAC and the MgAlFe-based LDH resulted in improved and abundant surface functional groups that favored a high uptake of phenol molecules from the aqueous phase through multiple mechanisms involving surface adsorption and $\pi-\pi$ interactions $[20,22,55]$. To further elaborate the possible adsorption mechanism of phenol, the energy of adsorption (E) was estimated from the linear form of the Dubinin-Radushkevich (DR) isotherm model $\left(\mathrm{R}^{2}=0.986\right)$ and characterization of SBAC-MgAlFe-LDH before and after phenol adsorption (Figures 1 and 2). The value of $\mathrm{E}$ at optimized adsorption conditions ( $\mathrm{pH} 6$, time $120 \mathrm{~min}$, and temperature $35^{\circ} \mathrm{C}$ ) is found to be $40.82(\mathrm{~kJ} / \mathrm{mol})$, suggesting that the possible main phenol adsorption mechanism onto SBAC-MgAlFe-LDH is involved in physisorption ( $\pi-\pi$ interactions) as a result of the phenol aromatic ring interaction with that of the SBAC-MgAlFe-LDH via charge transfer, dispersive-force, and polar attractions $[17,22,29,57]$. The -OH groups on the SBAC-MgAlFe-LDH surface (FTIR in Figure 1a) act as electron donors are susceptible to enhancing the aromatic-ring $\pi$-donating intensity, thereby increasing the phenol attraction onto the SBAC-MgAlFe-LDH [22,61]. Additionally, the well-established hydrophobicity of phenol provides another dimension of phenol uptake onto the SBAC-MgAlFe-LDH, as this property enhances the affinity 
between phenol and SBAC-MgAlFe-LDH [22,61]. Similar mechanisms for uptake phenol by sludge-based adsorbents have been postulated by other authors [22,29].

\section{Conclusions}

In this study, sewage sludge-based activated carbon (SBAC)-MgAlFe-LDH composite was synthesized and evaluated for the removal of phenol from the water via RSM modeling. The effect of operating conditions on phenol uptake capacity well fitted the reduced cubic model, whose temperature exerted a lower influence on the SBAC-MgAlFe-LDH phenol uptake performance compared to initial $\mathrm{pH}$ and initial phenol concentrations. While the pseudo-first-order and Avrami fractional models provided a better comparative representation of the phenol uptake kinetic, the Langmuir model fit the equilibrium data better. Compared with many other similar LDHs adsorbents in the literature, the obtained maximum adsorption of $216.76 \mathrm{mg} / \mathrm{g}$ indicates a significant improvement for phenol uptake by an SBAC-MgAlFe-LDH. This high uptake capacity exhibited by the SBACLDH was attributed to the effective synergetic effects of SBAC and the MgAlFe-based $\mathrm{LDH}$, which yielded improved and abundant surface functional groups that favored the uptake of phenol molecules from the aqueous phase. These results suggest the potential of SBAC-MgAlFe-LDH as an excellent material for the effective removal of phenol water.

Author Contributions: Conceptualization, N.D.M. and M.Z.; methodology, M.Z.; software, N.D.M., M.Z.; validation, I.I., N.D.M. and M.Z.; formal analysis, N.D.M.; investigation, M.Z. and I.I.; resources, N.D.M.; data curation, M.Z. and I.I.; writing-original draft preparation, N.D.M. and M.Z.; writing-review and editing, I.I.; visualization, I.I.; supervision, N.D.M.; project administration, N.D.M.; funding acquisition, N.D.M. All authors have read and agreed to the published version of the manuscript.

Funding: This work was fully funded by The King Abdul-Aziz City for Science and Technology (KACST) funding for Project No. 12-Env2229-46 under NSTIP through Imam Abdulrahman Bin Faisal University, Dammam, Saudi Arabia.

Institutional Review Board Statement: Not applicable.

Informed Consent Statement: Not applicable.

Data Availability Statement: Not applicable.

Acknowledgments: The supplementary support provided by the Deanship of Scientific Research (DSR) of Imam Abdulrahman Bin Faisal University, Dammam Saudi Arabia, through project\#2020112-ENG.

Conflicts of Interest: The authors declare no conflict of interest.

Sample Availability: Samples of the compounds are available from the authors.

\section{References}

1. Mu'azu, N.; Jarrah, N.; Zubair, M.; Alagha, O. Removal of Phenolic Compounds from Water Using Sewage Sludge-Based Activated Carbon Adsorption: A Review. Int. J. Environ. Res. Public Health 2017, 14, 1094. [CrossRef]

2. USEPA. 2006 Edition of the Drinking Water Standards and Health Advisories; No. EPA 822-R-06-013; Office of Water U.S. Environmental Protection Agency: Washington, DC, USA, 2006. Available online: https://health.umsu.ac.ir/uploads/epa_drinking_water_ standard.pdf (accessed on 1 March 2018).

3. Mu'azu, N.D.; Alagha, O.; Anil, I. Systematic Modeling of Municipal Wastewater Activated Sludge Process and Treatment Plant Capacity Analysis Using GPS-X. Sustainability 2020, 12, 8182. [CrossRef]

4. Ping, F.; Chaoping, C.; Dingsheng, C.; Zhixiong, T. Carbonaceous adsorbents prepared from sewage sludge and its application for $\mathrm{Hg} 0$ adsorption in simulated flue gas. Chin. J. Chem. Eng. 2010, 18, 231-238.

5. Silva, T.L.; Ronix, A.; Pezoti, O.; Souza, L.S.; Leandro, P.K.T.; Bedin, K.C.; Beltrame, K.K.; Cazetta, A.L.; Almeida, V.C. Mesoporous activated carbon from industrial laundry sewage sludge: Adsorption studies of reactive dye Remazol Brilliant Blue R. Chem. Eng. J. 2016, 303, 467-476. [CrossRef]

6. Zubair, M.; Ihsanullah, I.; Aziz, H.A.; Ahmad, M.A.; Al-Harthi, M.A. Sustainable wastewater treatment by biochar/layered double hydroxide composites: Progress, challenges, and outlook. Bioresour. Technol. 2020, 319, 124128. [CrossRef]

7. Zubair, M.; Daud, M.; McKay, G.; Shehzad, F.; Al-Harthi, M.A. Recent progress in layered double hydroxides (LDH)-containing hybrids as adsorbents for water remediation. Appl. Clay Sci. 2017, 143, 279-292. [CrossRef] 
8. Mu'azu, N.D.; Jarrah, N.; Kazeem, T.S.; Zubair, M.; Al-Harthi, M. Bentonite-layered double hydroxide composite for enhanced aqueous adsorption of Eriochrome Black T. Appl. Clay Sci. 2018, 161, 23-34. [CrossRef]

9. Zubair, M.; Jarrah, N.; Khalid, A.; Manzar, M.S.; Kazeem, T.S.; Al-Harthi, M.A. Starch-NiFe-layered double hydroxide composites: Efficient removal of methyl orange from aqueous phase. J. Mol. Liq. 2018, 249, 254-264. [CrossRef]

10. Kazeem, T.S.; Zubair, M.; Daud, M.; Mu'azu, N.D.; Al-Harthi, M.A. Graphene/ternary layered double hydroxide composites: Efficient removal of anionic dye from aqueous phase. Korean J. Chem. Eng. 2019, 36, 1057-1068. [CrossRef]

11. Contreras-Ruiz, J.C.; Martínez-Gallegos, S.; García-Rivas, J.L.; Illescas, J.; González-Juárez, J.C.; Macedo Miranda, G.; Ordoñez Regil, E. Influence of the Textural Parameters of $\mathrm{LDH}-\mathrm{TiO}_{2}$ Composites on Phenol Adsorption and Photodegradation Capacities. Int. J. Photoenergy 2019, 2019, 5783507. [CrossRef]

12. Blaisi, N.I.; Zubair, M. Date palm ash-MgAl-layered double hydroxide composite: Sustainable adsorbent for effective removal of methyl orange and eriochrome black-T from aqueous phase. Environ. Sci. Pollut. Res. 2018, 25, 34319-34331. [CrossRef]

13. Mu'azu, N.D.; Jarrah, N.; Zubair, M.; Manzar, M.S.; Kazeem, T.S.; Qureshi, A.; Haladu, S.A.; Blaisi, N.I.; Essa, M.H.; Al-Harthi, M.A. Mechanistic aspects of magnetic MgAlNi barium-ferrite nanocomposites enhanced adsorptive removal of an anionic dye from aqueous phase. J. Saudi Chem. Soc. 2020, 24, 715-732. [CrossRef]

14. Xu, H.; Zhu, S.; Xia, M.; Wang, F. Rapid and efficient removal of diclofenac sodium from aqueous solution via ternary core-shell CS@PANI@LDH composite: Experimental and adsorption mechanism study. J. Hazard. Mater. 2021, 402, 123815. [CrossRef] [PubMed]

15. Drewnowski, J.; Szelagg, B.; Xie, L.; Lu, X.; Ganesapillai, M.; Deb, C.K.; Szulżyk-Cieplak, J.; Łagód, G. The Influence of COD Fraction Forms and Molecules Size on Hydrolysis Process Developed by Comparative OUR Studies in Activated Sludge Modelling. Molecules 2020, 25, 929. [CrossRef]

16. Kameda, T.; Horikoshi, K.; Kikuchi, H.; Kitagawa, F.; Kumagai, S.; Saito, Y.; Kondo, M.; Jimbo, Y.; Yoshioka, T. Kinetic and equilibrium analyses of lactate adsorption by $\mathrm{Cu}-\mathrm{Al}$ and $\mathrm{Mg}-\mathrm{Al}$ layered double hydroxides (Cu-Al $\mathrm{LDH}$ and $\mathrm{Mg}-\mathrm{Al} \mathrm{LDH})$ and $\mathrm{Cu}-\mathrm{Al}$ and $\mathrm{Mg}-\mathrm{Al}$ layered double oxides (Cu-Al LDO and Mg-Al LDO). Nano-Struct. Nano-Objects 2021, 25, 100656. [CrossRef]

17. Mu'azu, N.D.; Zubair, M.; Jarrah, N.; Alagha, O.; Al-Harthi, M.A.; Essa, M.H. Sewage Sludge ZnCl2-Activated Carbon Intercalated MgFe-LDH Nanocomposites: Insight of the Sorption Mechanism of Improved Removal of Phenol from Water. Int. J. Mol. Sci. 2020, 21, 1563. [CrossRef]

18. Juretic, D.; Kusic, H.; Dionysiou, D.D.; Bozic, A.L. Environmental aspects of photooxidative treatment of phenolic compounds. J. Hazard. Mater. 2013, 262, 377-386. [CrossRef]

19. Sun, Y.; Zhou, J.; Cai, W.; Zhao, R.; Yuan, J. Hierarchically porous NiAl-LDH nanoparticles as highly efficient adsorbent for p-nitrophenol from water. Appl. Surf. Sci. 2015, 349, 897-903. [CrossRef]

20. He, X.; Wang, B.; Zhang, Q. Phenols removal from water by precursor preparation for MgAl layered double hydroxide: Isotherm, kinetic and mechanism. Mater. Chem. Phys. 2019, 221, 108-117. [CrossRef]

21. Zhang, Z.; Sun, D.; Li, G.; Zhang, B.; Zhang, B.; Qiu, S.; Li, Y.; Wu, T. Calcined products of Mg-Al layered double hydroxides/single-walled carbon nanotubes nanocomposites for expeditious removal of phenol and 4-chlorophenol from aqueous solutions. Colloids Surf. A Physicochem. Eng. Asp. 2019, 565, 143-153. [CrossRef]

22. Dos Reis, G.S.; Adebayo, M.A.; Sampaio, C.H.; Lima, E.C.; Thue, P.S.; de Brum, I.A.S.; Dias, S.L.P.; Pavan, F.A. Removal of phenolic compounds from aqueous solutions using sludge-based activated carbons prepared by conventional heating and microwave-assisted pyrolysis. Water Air Soil Pollut. 2017, 228, 33. [CrossRef]

23. Sierra, I.; Iriarte-Velasco, U.; Gamero, M.; Aguayo, A.T. Upgrading of sewage sludge by demineralization and physical activation with $\mathrm{CO}_{2}$ : Application for methylene blue and phenol removal. Microporous Mesoporous Mater. 2017, 250, 88-99. [CrossRef]

24. Rozada, F.; Otero, M.; Parra, J.B.; Morán, A.; García, A.I. Producing adsorbents from sewage sludge and discarded tyres: Characterization and utilization for the removal of pollutants from water. Chem. Eng. J. 2005, 114, 161-169. [CrossRef]

25. Liadi, M.A.; Mu'azu, N.D.; Jarrah, N.; Zubair, M.; Alagha, O.; Al-Harthi, M.A.; Essa, M.H. Comparative performance study of $\mathrm{ZnCl}_{2}$ and $\mathrm{NaOH}$ sludge based activated carbon for simultaneous aqueous uptake of phenolic compounds. Int. J. Environ. Anal. Chem. 2020, 1-25. [CrossRef]

26. Kong, L.; Xiong, Y.; Sun, L.; Tian, S.; Xu, X.; Zhao, C.; Luo, R.; Yang, X.; Shih, K.; Liu, H. Sorption performance and mechanism of a sludge-derived char as porous carbon-based hybrid adsorbent for benzene derivatives in aqueous solution. J. Hazard. Mater. 2014, 274, 205-211. [CrossRef]

27. Zou, J.; Dai, Y.; Wang, X.; Ren, Z.; Tian, C.; Pan, K.; Li, S.; Abuobeidah, M.; Fu, H. Structure and adsorption properties of sewage sludge-derived carbon with removal of inorganic impurities and high porosity. Bioresour. Technol. 2013, 142, 209-217. [CrossRef] [PubMed]

28. Bousba, S.; Meniai, A.H. Removal of phenol from water by adsorption onto sewage sludge based adsorbent. Chem. Eng. Trans. 2014, 40, 235-240. [CrossRef]

29. Xin, W.; Li, X.; Song, Y. Facile synthesis of sludge-based mesoporous carbon with flocculants: Effect of template on the synthetic behavior and improved phenol capture. J. Clean. Prod. 2021, 282, 124458. [CrossRef]

30. Manzar, M.S.; Khan, G.; dos Santos Lins, P.V.; Zubair, M.; Khan, S.U.; Selvasembian, R.; Meili, L.; Blaisi, N.I.; Nawaz, M.; Abdul Aziz, H.; et al. RSM-CCD optimization approach for the adsorptive removal of Eriochrome Black T from aqueous system using steel slag-based adsorbent: Characterization, Isotherm, Kinetic modeling and thermodynamic analysis. J. Mol. Liq. 2021, 339, 116714. [CrossRef] 
31. Haladu, S.A.; Mu'azu, N.D.; Jarrah, N.; Zubair, M.; Ali, S.A. Investigation of biodegradable polyaspartate as an effective chelant for washing of lead from soil: Response surface methodology approach. Int. J. Environ. Anal. Chem. 2020, 1-18. [CrossRef]

32. Usman, A.K.; Mu'azu, N.D.; Lukman, S.; Essa, M.H.; Bukhari, A.A.; Al-Malack, M.H. Removal of Lead and Copper from Contaminated Mixed Clay Soils Using Pulsed Electrokinetics. Soil Sediment Contam. Int. J. 2020, 29, 465-480. [CrossRef]

33. Myers, R.H.; Montgomery, D.C.; Anderson-Cook, C.M. Response Surface Methodology: Process and Product Optimization Using Designed Experiments; John Wiley \& Sons: New York, NY, USA, 2016; ISBN 1118916034.

34. Anderson, M.J.; Whitcomb, P.J. RSM Simplified: Optimizing Processes Using Response Surface Methods for Design of Experiments; Productivity Press: New York, NY, USA, 2016; ISBN 1498745997.

35. Alagha, O.; Manzar, M.S.; Zubair, M.; Anil, I.; Mu'azu, N.D.; Qureshi, A. Magnetic Mg-Fe/LDH intercalated activated carbon composites for nitrate and phosphate removal from wastewater: Insight into behavior and mechanisms. Nanomaterials 2020, 10, 1361. [CrossRef] [PubMed]

36. Mu'azu, N.D.; Essa, M.H.; Lukman, S. Augmenting granular activated carbon with natural clay for multicomponent sorption of heavy metals from aqueous solutions. Water Sci. Technol. 2017, 76, 2213-2221. [CrossRef]

37. Mu'azu, N.D.; Jarrah, N.; Zubair, M.; Manzar, M.S.; Kazeem, T.S.; Al-Harthi, M. Evaluation of novel Mg/Al/Ni-BaFe ternary layered hydroxides uptake of methyl orange dye from water. Korean J. Chem. Eng. 2019, 36, 2008-2022. [CrossRef]

38. Ait-Amir, B.; Pougnet, P.; El Hami, A. 6-Meta-Model Development. In Embedded Mechatronic Systems 2, 2nd ed.; El Hami, A., Pougnet, P., Eds.; ISTE: London, UK, 2020; pp. 157-187. ISBN 978-1-78548-190-1.

39. Ho, Y.S.; McKay, G. A Comparison of Chemisorption Kinetic Models Applied to Pollutant Removal on Various Sorbents. Process Saf. Environ. Prot. 1998, 76, 332-340. [CrossRef]

40. Weber, W.J.; Morris, J.C. Kinetics of adsorption on carbon from solution. J. Sanit. Eng. Div. 1963, 89, 31-60. [CrossRef]

41. Avrami, M. Kinetics of phase change. I General theory. J. Chem. Phys. 1939, 7, 1103-1112. [CrossRef]

42. Johnson, R.D.; Arnold, F.H. The Temkin isotherm describes heterogeneous protein adsorption. Biochim. Biophys. Acta (BBA) Protein Struct. Mol. Enzymol. 1995, 1247, 293-297. [CrossRef]

43. Freundlich, H.M.F. Over the adsorption in solution. J. Phys. Chem. 1906, 57, 1100-1107.

44. Redlich, O.; Peterson, D.L. A useful adsorption isotherm. J. Phys. Chem. 1959, 63, 1024. [CrossRef]

45. Langmuir, I. The constitution and fundamental properties of solids and liquids. Part, I. Solids. J. Am. Chem. Soc. 1916, 38, 2221-2295. [CrossRef]

46. Liu, Y.; $\mathrm{Xu}, \mathrm{H}$.; Yang, S.-F.; Tay, J.-H. A general model for biosorption of $\mathrm{Cd}^{2+}, \mathrm{Cu}^{2+}$ and $\mathrm{Zn}^{2+}$ by aerobic granules. J. Biotechnol. 2003, 102, 233-239. [CrossRef]

47. Zubair, M.; Manzar, M.S.; Mu'azu, N.D.; Anil, I.; Blaisi, N.I.; Al-Harthi, M.A. Functionalized MgAl-layered hydroxide intercalated date-palm biochar for Enhanced Uptake of Cationic dye: Kinetics, isotherm and thermodynamic studies. Appl. Clay Sci. 2020, 190, 105587. [CrossRef]

48. Zubair, M.; Mu'azu, N.D.; Jarrah, N.; Blaisi, N.; Aziz, H.A.; Al-Harthi, M.A. Adsorption Behavior and Mechanism of Methylene Blue, Crystal Violet, Eriochrome Black T, and Methyl Orange Dyes onto Biochar-Derived Date Palm Fronds Waste Produced at Different Pyrolysis Conditions. Water Air Soil Pollut. 2020, 231, 240. [CrossRef]

49. Hermosin, M.C.; Pavlovic, I.; Ulibarri, M.A.; Cornejo, J. Trichlorophenol adsorption on layered double hydroxide: A potential sorbent. J. Environ. Sci. Health Part A 1993, 28, 1875-1888. [CrossRef]

50. Li, Y.; Bi, H.Y.; Mao, X.M.; Liang, Y.Q.; Li, H. Adsorption behavior and mechanism of core-shell magnetic rhamnolipid-layered double hydroxide nanohybrid for phenolic compounds from heavy metal-phenolic pollutants. Appl. Clay Sci. 2018, 162, 230-238. [CrossRef]

51. Lukman, S.; Bukhari, A.; Al-Malack, M.H.; Mu'Azu, N.D.; Essa, M.H. Geochemical modeling of trivalent chromium migration in saline-sodic soil during Lasagna process: Impact on soil physicochemical properties. Sci. World J. 2014, 20. [CrossRef]

52. Anderson, M.J.; Whitcomb, P.J. DOE Simplified: Practical Tools for Effective Experimentation; CRC Press: Boca Raton, FL, USA, 2017; ISBN 1498730906.

53. Mu'azu, N.D.; Haladu, S.A.; Jarrah, N.; Zubair, M.; Essa, M.H.; Ali, S.A. Polyaspartate extraction of cadmium ions from contaminated soil: Evaluation and optimization using central composite design. J. Hazard. Mater. 2018, 342, 58-68. [CrossRef]

54. Khalid, A.; Zubair, M. A comparative study on the adsorption of Eriochrome Black T dye from aqueous solution on graphene and acid-modified graphene. Arab. J. Sci. Eng. 2018, 43, 2167-2179. [CrossRef]

55. Lupa, L.; Cocheci, L.; Pode, R.; Hulka, I. Phenol adsorption using Aliquat 336 functionalized Zn-Al layered double hydroxide. Sep. Purif. Technol. 2018, 196, 82-95. [CrossRef]

56. Amayreh, M.; Chanbasha, B.; Alhooshani, K.; Mu'azu, N.D.; Lee, H.K. Determination of N-nitrosamines by automated dispersive liquid-liquid microextraction integrated with gas chromatography and mass spectrometry. J. Sep. Sci. 2015, 38, 1741-1748. [CrossRef] [PubMed]

57. Thue, P.S.; Adebayo, M.A.; Lima, E.C.; Sieliechi, J.M.; Machado, F.M.; Dotto, G.L.; Vaghetti, J.C.P.; Dias, S.L.P. Preparation, characterization and application of microwave-assisted activated carbons from wood chips for removal of phenol from aqueous solution. J. Mol. Liq. 2016, 223, 1067-1080. [CrossRef]

58. Manzar, M.S.; Zubair, M.; Khan, N.A.; Husain Khan, A.; Baig, U.; Aziz, M.A.; Blaisi, N.I.; Abdel-Magid, H.I.M. Adsorption behaviour of green coffee residues for decolourization of hazardous congo red and eriochrome black $\mathrm{T}$ dyes from aqueous solutions. Int. J. Environ. Anal. Chem. 2020. [CrossRef] 
59. Yu, Y.; Zhuang, Y.-Y.; Wang, Z.-H.; Qiu, M.-Q. Adsorption of water-soluble dyes onto modified resin. Chemosphere 2004, 54, 425-430. [CrossRef]

60. Luo, Z.; Gao, M.; Yang, S.; Yang, Q. Adsorption of phenols on reduced-charge montmorillonites modified by bispyridinium dibromides: Mechanism, kinetics and thermodynamics studies. Colloids Surf. A Physicochem. Eng. Asp. 2015, 482, 222-230. [CrossRef]

61. Liu, Q.-S.; Zheng, T.; Wang, P.; Jiang, J.-P.; Li, N. Adsorption isotherm, kinetic and mechanism studies of some substituted phenols on activated carbon fibers. Chem. Eng. J. 2010, 157, 348-356. [CrossRef] 